\title{
Article \\ Multicomponent Solids of DL-2-Hydroxy-2-phenylacetic Acid and Pyridinecarboxamides
}

\author{
Alfonso Castiñeiras ${ }^{1, *(1)}$, Antonio Frontera ${ }^{2}{ }^{\oplus}$, Isabel García-Santos ${ }^{1}{ }^{\circledR}$, Josefa M. González-Pérez ${ }^{3}$, \\ Juan Niclós-Gutiérrez ${ }^{3}$ and Rocío Torres-Iglesias ${ }^{1}$
}

1 Department of Inorganic Chemistry, Faculty of Pharmacy, University of Santiago de Compostela, 15782 Santiago de Compostela, Spain; isabel.garcia@usc.es (I.G.-S.); rocio.torres.iglesias@rai.usc.es (R.T.-I.)

2 Department of Química, Universitat de les Illes Balears, Crta. De Valldemossa km 7.5, 07122 Palma de Mallorca, Spain; toni.frontera@uib.es

3 Department of Inorganic Chemistry, Faculty of Pharmacy, University of Granada, 18071 Granada, Spain; jmgp@ugr.es (J.M.G.-P.); jniclos@ugr.es (J.N.-G.)

* Correspondence: alfonso.castineiras@usc.es

check for

updates

Citation: Castiñeiras, A.; Frontera, A.; García-Santos, I.; González-Pérez, J.M.; Niclós-Gutiérrez, J.; Torres-Iglesias, R. Multicomponent Solids of DL-2-Hydroxy-2phenylacetic Acid and Pyridinecarboxamides. Crystals 2022, 12, 142. https://doi.org/10.3390/ cryst12020142

Academic Editor: Klaus Merz

Received: 10 December 2021

Accepted: 5 January 2022

Published: 20 January 2022

Publisher's Note: MDPI stays neutral with regard to jurisdictional claims in published maps and institutional affiliations.

Copyright: (c) 2022 by the authors Licensee MDPI, Basel, Switzerland. This article is an open access article distributed under the terms and conditions of the Creative Commons Attribution (CC BY) license (https:// creativecommons.org/licenses/by/ $4.0 /)$.

\begin{abstract}
We prepared cocrystals of DL-2-Hydroxy-2-phenylacetic acid (D, L- $\left.\mathbf{H}_{\mathbf{2}} \mathbf{m a}\right)$ with the pyridinecarboxamide isomers, picolinamide (pic) and isonicotinamide (inam). They were characterized by elemental analysis, single crystal and powder $\mathrm{X}$-ray, IR spectroscopy and ${ }^{1} \mathrm{H}$ and ${ }^{13} \mathrm{C}$

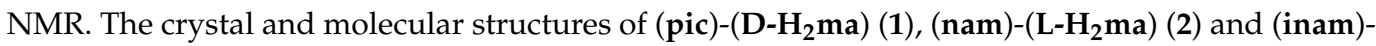
$\left(\mathbf{L}-\mathbf{H}_{2} \mathbf{m a}\right.$ ) (3) were studied. The crystal packing is stabilized primarily by hydrogen bonding and in some cases through $\pi-\pi$ stacking interactions. The analysis of crystal structures reveals the existence of the characteristic heterosynthons with the binding motif $R_{2}^{2}(8)$ (primary amide-carboxilic acid) between pyridinecarboxamide molecules and the acid. Other synthons involve hydrogen bonds such as $\mathrm{O}-\mathrm{H}_{\text {(carboxyl) }} \cdots \mathrm{N}_{\text {(pyridine) }}$ and $\mathrm{O}-\mathrm{H}_{\text {(hydroxyl) }} \cdots \mathrm{N}_{\text {(pyridine) }}$ depending on the isomer. The packing of 1 and 3 is formed by tetramers, for whose formation a crystallization mechanism based on two stages is proposed, involving an amide-acid (1) or amide-amide (3) molecular recognition in the first stage and the formation of others, and interdimeric hydrogen bonding interactions in the second. The thermal stability of the cocrystals was studied by differential scanning calorimetry and thermogravimetry. Further studies were conducted to evaluate other physicochemical properties of the cocrystals in comparison to the pure coformers. Density-functional theory (DFT) calculations (including NCIplot and QTAIM analyses) were performed to further characterize and rationalize the noncovalent interactions.
\end{abstract}

Keywords: pyridinecarboxamides; cocrystals; mandelic acid; X-ray structure; DFT calculations

\section{Introduction}

Crystal engineering is the rational design of functional molecular solids from neutral or ionic building blocks, using intermolecular interactions in the design strategy [1]. This field has its origins in organic chemistry and in physical chemistry. The expansion of crystal engineering during the last years as a research field parallels significant interest in the origin and nature of intermolecular interactions and their use in the design and preparation of new crystalline structures [2].

The concept of crystal engineering, mainly cocrystal, is gaining an extensive interest of pharmaceutical researchers of both academia and industry during the last decade [3], the prominent reason being its ability to enhance the physicochemical and biopharmaceutical properties of active pharmaceutical ingredients without altering chemical structure, thus maintaining its therapeutic activity. With the new guidelines issued by United States Food and Drug Administration and European Medicines Agency for the regulatory aspect of cocrystal, the development of pharmaceutical cocrystal has gained a high impetus [4]. 
A supramolecular synthesis is used to prepare cocrystals, and the design of homo and supramolecular heterosynthons is particularly one of the most exploited [5,6]. Although the preparation of cocrystals does not involve great complexity, the selection of the solvent can be critical in obtaining a particular crystal phase of cocrystal. The role of the solvent in the nucleation of crystals and cocrystals is still far from being completely understood.

The three isomers of pyridinecarboxamide: 2-pyridine carboxamide or picolinamide (pic), 3-pyridinecarboxamide or nicotinamide (nam) and 4-pyridinecarboxamide or isonicotinamide (inam) (Scheme 1), are a class of medicinal agents that can be classified as GRAS compounds (generally regarded as safe). Nicotinamide and isonicotinamide are popular cocrystal formers, nam is vitamin B3 and therefore of pharmaceutical relevance [7], whilst isonicotinamide is one of the most effectively used cocrystallizing compounds [8], as the pyridine $\mathrm{N}$ atom of the isonicotinamide molecule readily acts as a hydrogen bond acceptor when faced with good hydrogen bond donors such as carboxylic acids and alcohols [9]. In fact, the carboxylic acid ...pyridine hydrogen bond has been identified as a robust yet versatile hydrogen bond and persists even in the presence of other good donors [10]. Cocrystals of picolinamide are rarely seen in the literature, despite being a structural isomer of nam and inam and a strong inhibitor of poly(ADP-ribose)synthetase [11], showing important biological activity with a coenzyme called NAD (nicotinamide adenine dinucleotide), which plays important roles in more than 200 amino acid and carbohydrate metabolic reactions [12]. Apart from pharmaceutical value, in general, pyridinecarboxamides are excellent cocrystallizing compounds. The amide group features two hydrogen bond donors and two lone pairs on the carbonyl $\mathrm{O}$ atom. A second hydrogen bond acceptor is the lone pair on the $\mathrm{N}$ atom of the pyridine ring. Consequently, these molecules are very versatile for a variety of hydrogen bonding interactions, especially in pharmaceutical cocrystals [13]. The crystal and molecular structures of the three isomers have been the subject of recent studies, and from the crystal structure point of view, all isomer compounds exhibit polymorphism. Two polymorphs are known of picolinamide [14] nicotinamide, which is a highly polymorphic compound with nine solved single-crystal structures [15], and isonicotinamide has six polymorphs in monoclinic and orthorhombic forms [16-19].<smiles>NC(=O)c1ccccn1</smiles>

picolinamide, pic<smiles>NC(=O)c1cccnc1</smiles>

nicotinamide, nam<smiles>NC(=O)c1ccncc1</smiles>

isonicotinamide, inam<smiles>O=C(O)[C@@H](O)c1ccccc1</smiles>

(R)-mandelic acid, $\mathbf{R}-\mathbf{H}_{\mathbf{2}} \mathbf{m a}$<smiles>O=C(O)C(=O)c1ccccc1</smiles>

(S)-mandelic acid, $\mathbf{S}-\mathbf{H}_{\mathbf{2}} \mathbf{m a}$

Scheme 1. Molecular diagrams of pyridinecarboxamides and mandelic acid. $\theta_{1}, \theta_{2}$ and $\theta_{3}$ indicate angles of torsion.

DL-Mandelic acid (Scheme 1) is a useful precursor to various drugs, for example homatropine and cyclandelate, which are esters of mandelic acid, and it is also known to have antibacterial properties [20]. Generally, the profile of DL- $\mathbf{H}_{2} \mathbf{m a}$ allows us to envisage this compound as an excellent coformer for cocrystals with the aforementioned 
carboxamides. Indeed, given that $\mathbf{D L}-\mathbf{H}_{2}$ ma is a substituted carboxylic acid containing a hydroxyl group on the adjacent carbon, it also possesses a set of sites capable of hydrogen bonding, both of donor and acceptor character.

For racemate of mandelic acid DL- $\mathbf{H}_{2}$ ma and its enantiomers $\mathbf{L}-\mathbf{H}_{\mathbf{2}} \mathbf{m a}$ and D-H $\mathbf{m}$ a, different polymorphs are known. Racemic DL- $\mathbf{H}_{2}$ ma occurs as orthorhombic form I and also as polymorph II, monoclinic, metastable at normal conditions [21,22]. From $\mathbf{D}-\mathbf{H}_{\mathbf{2}} \mathbf{m a}$ only one monoclinic form is known [23] and for $\mathbf{L}-\mathbf{H}_{2} \mathbf{m a}$ two polymorphs are known, both monoclinic [22].

Taking into account the previous considerations, the main objective of this work is the preparation, characterization, study of physicochemical properties, and identification of recurrent supramolecular patterns, within a new set of multicomponent pharmaceutical crystals that involve the three isomers of pyridinecarboxamide with DL-mandelic acid as coformer (Scheme 1), as well as to evaluate the effect of position isomerism of cocrystal formers on the formation and robustness of the supramolecular structures and subsequent physicochemical properties of cocrystals.

\section{Experimental Part}

\subsection{Materials and Physical Measurements}

DL-Mandelic acid and the pyridinecarboxamide isomers were purchased from SigmaAldrich (Sigma-Aldrich. Inc., Tres Cantos, Madrid, Spain). Commercially available solvents were used as received without further purification. Melting points were determined on a Büchi melting point apparatus (Büchi Labortechnik AG-Flawil, Switzerland) and are uncorrected. Elemental analyses for carbon, hydrogen and nitrogen were performed with a Fisons-Carlo Erba 1108 microanalyser (CARLO ERBA Reagents SAS, Chaussée du Vexin, France). ${ }^{1} \mathrm{H}$ NMR and ${ }^{13} \mathrm{C}$ NMR spectra in DMSO-d 6 were run on a Varian Mercury 300 instrument (Varian Medical Systems, Inc., Palo Alto, CA, USA), using TMS as the internal reference. IR spectra were recorded as $\mathrm{KBr}$ pellets $\left(4000-400 \mathrm{~cm}^{-1}\right)$ on a Bruker IFS-66v spectrophotometer (Bruker Corporation, Billerica, MA, USA). TGA experiments were carried out on a Shimadzu Thermobalance TGA-DTG-50H Instrument (TA Instruments, New Castle, DE, EE. UU.) from room temperature to $700{ }^{\circ} \mathrm{C}$ in a flow of air $\left(100 \mathrm{~mL} \mathrm{~min}^{-1}\right)$ and series of FTIR spectra (20-30 per sample) of evolved gasses were recorded using a coupled FT-IR Nicolet Magma 550 spectrophotometer (Thermo Fisher Scientific, Waltham, MA, USA). Differential scanning calorimetry (DSC) was conducted on a DSC Q100 apparatus of TA Instruments. Accurately weighed samples (1-2 mg) were placed in hermetically sealed aluminum crucibles $(40 \mathrm{~mL})$ and scanned from 0 to $350{ }^{\circ} \mathrm{C}$ at a heating rate of

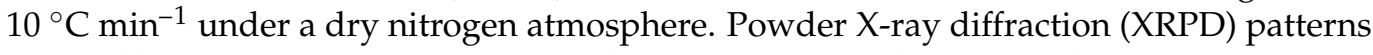
were collected on a Philips PW1710 (Philips Engineering Solutions, Aachen, Germany) with a $\mathrm{Cu}-\mathrm{K} \alpha$ radiation $(1.5406 \AA)$. The tube voltage and amperage were set at $40 \mathrm{kV}$ and $30 \mathrm{~mA}$, respectively. Each sample was scanned between 2 and $50^{\circ} 2 \theta$ with a step size of $0.02^{\circ}$. The instrument was previously calibrated using a silicon standard.

\subsection{Cocrystal Screening}

Compounds were prepared by cocrystallization via solvent-drop grinding: Stoichiometric amounts of $\mathbf{D L}-\mathbf{H}_{2}$ ma with pic, or inam were ground with a mortar and pestle for ca. 5-7 min with the addition of $10 \mu \mathrm{L}$ of Ethyl acetate per $50 \mathrm{mg}$ of cocrystal formers. The clear, nonsaturated resulting solutions were poured into a $5 \mathrm{~mL}$ vial and left to evaporate slowly under ambient conditions until cocrystals formed. The single crystals of (pic)-(D- $\left.\mathbf{H}_{\mathbf{2}} \mathbf{m a}\right) \mathbf{( 1 )}$ and (inam)-( $\left.\mathbf{L}-\mathbf{H}_{2} \mathbf{m a}\right)$ (3), suitable for X-ray diffraction studies, were obtained in 2-15 days from Ethyl acetate.

Preparation of the cocrystals was also attempted with other solvents, such as dichloromethane, formamide, DMF, chloroform, acetonitrile, isopropyl alcohol, cyclohexane, ethanol, methanol, $\mathrm{CCl}_{4}, \mathrm{THF}$ and toluene, but the yield was lower. 


\subsection{Cocrystal Synthesis}

(pic)-(D-H $\mathrm{H}_{2}$ ) (1). DL-mandelic acid $(0.152 \mathrm{~g}, 1.0 \mathrm{mmol})$ and picolinamide $(0.122 \mathrm{~g}$, $1.0 \mathrm{mmol})$. Ethyl acetate $(3 \mathrm{~mL})$. Colorless crystals after one day. M.p. $\left({ }^{\circ} \mathrm{C}\right): 88-92$. Elemental analysis: Found: $\mathrm{C}, 59.72 ; \mathrm{H}, 5.10 ; \mathrm{N}, 10.27$. Calculated (\%) for $\mathrm{C}_{14} \mathrm{H}_{14} \mathrm{~N}_{2} \mathrm{O}_{4}$ : C, 61.31; $\mathrm{H}$, 5.45; N, 10.21. IR $\left(v_{\max } / \mathrm{cm}^{-1}\right): 3471-3435 v\left(\mathrm{NH}_{2}\right), v(\mathrm{OH}), 3282 v\left(\mathrm{NH}_{2}\right), 1695-1633 v(\mathrm{C}=\mathrm{O})$, $1589,1570,1418 v(\mathrm{CN}), 1293,1269,1187,1107,1066-1012$ v(C-O), 995, 755, 725, 697, 645-616 $\alpha(\mathrm{CCC}), 600 .{ }^{1} \mathrm{H}$ NMR (DMSO-d $\left.{ }_{6}, \mathrm{ppm}\right): 12.50$ (br, 1H, COOH), 8.62 (m, 1H, py), 8.12 (s, $\left.1 \mathrm{H}, \mathrm{NH}_{2}\right), 8.05-7.97(\mathrm{~m}, 2 \mathrm{H}, \mathrm{py}), 7.64\left(\mathrm{~s}, 1 \mathrm{H}, \mathrm{NH}_{2}\right), 7.65-7.58(\mathrm{~m}, 5 \mathrm{H}$, ring $), 5.86(\mathrm{~s}, 1 \mathrm{H}, \mathrm{CH})$, 5.02 (s, 1H, OH). ${ }^{13} \mathrm{C}$ NMR (DMSO-d $\left.6, \mathrm{ppm}\right): 174.3$ (C1), 166.3 (C11), 150.4 (C12), 140.4 (C3), 137.8 (C14), 128.3 (C3, C7), 127.8 (C6), 126.8 (C4, C8), 126.6 (C15), 122.0 (C13), 72.4 (C2).

(inam)-( $\left(-\mathrm{H}_{2} \mathrm{ma}\right)$ (3). DL-mandelic acid $(0.152 \mathrm{~g}, 1.0 \mathrm{mmol})$ and isonicotinamide $(0.122 \mathrm{~g}, 1.0 \mathrm{mmol})$. Ethyl acetate $(11 \mathrm{~mL})$. Colorless crystals after one day. M.p. $\left({ }^{\circ} \mathrm{C}\right): 107-$ 114. Elemental analysis: Found: $\mathrm{C}, 59.89 ; \mathrm{H}, 4.85 ; \mathrm{N}, 10.55$. Calculated $(\%)$ for $\mathrm{C}_{14} \mathrm{H}_{16} \mathrm{~N}_{2} \mathrm{O}_{4}$ : C, 61.31; H, 5.45; N, 10.21. IR $\left(v_{\max } / \mathrm{cm}^{-1}\right)$ : 3424-3379 $v\left(\mathrm{NH}_{2}\right), v(\mathrm{OH}), 3162 v\left(\mathrm{NH}_{2}\right), 1729$, 1694-1604 v(C=O), 1555, 1420-1407 v(CN), 1303, 1227, 1188, 1065-1018 v(C-O), 756, 737, 695, $647 \alpha(\mathrm{CCC}), 606 .{ }^{1} \mathrm{H}$ NMR (DMSO-d $\left.6, \mathrm{ppm}\right): 12.53$ (br, 1H, COOH), 8.70-8.60(m, 2H, py), $8.22\left(\mathrm{~s}, 1 \mathrm{H}, \mathrm{NH}_{2}\right), 7.75-7.70(\mathrm{~m}, 3 \mathrm{H}, \mathrm{py}) 7.40\left(\mathrm{~s}, 1 \mathrm{H}, \mathrm{NH}_{2}\right), 7.37-7.23(\mathrm{~m}, 5 \mathrm{H}, \mathrm{ring}), 5.82$ (s, 1H, CH), 4.99 (s, 1H, OH). ${ }^{13} \mathrm{C}$ NMR (DMSO-d $\left.6, \mathrm{ppm}\right): 174.3$ (C1), 166.5 (C11), 150.4 (C14, C16), 140.3 (C12), 128.2 (C3, C7), 127.7 (C6), 126.7 (C4, C8), 121.5 (C13, C17), 72.4 (C2).

\subsection{Solubility Determination}

The water solubility of each cocrystal was determined in triplicate, and compared with that of the corresponding pyridinecarboxamides coformer. For this, a quantitative method based on the saturation of solutions at room temperature was used as follows: An excess of coformer or cocrystal was dispersed in 0.5 or $1 \mathrm{~mL}$ of Milli-Q water in Eppendorf tubes and left stirring for a week at room temperature. The samples were centrifuged at 12,000 rpm for $45 \mathrm{~min}$, in each case the supernatant liquid was removed, and the corresponding solid was dried and weighed. This led us first to determine the solubility for pic $(\mathrm{S}=177 \mathrm{mg} / \mathrm{mL})$, nam $(S=500 \mathrm{mg} / \mathrm{mL})$, inam $(S=192 \mathrm{mg} / \mathrm{mL})$ and $\mathbf{D L}-\mathbf{H}_{\mathbf{2}} \mathbf{m a}(\mathrm{S}=159 \mathrm{mg} / \mathrm{mL})$, and then that of their respective cocrystals.

\subsection{Theoretical Methods}

Calculations of the noncovalent interactions were performed using the Gaussian16 [24] program and the PBE0-D3/def2-TZVP level of theory [25-27]. To evaluate the interactions in the solid state, the crystallographic coordinates were used apart from the positions of the H-atoms, which were optimized at the same level. The interaction energies were calculated with correction for the basis set superposition error (BSSE) using the Boys-Bernardi counterpoise technique [28]. Bader's quantum theory "atoms in molecules" theory (QTAIM) and noncovalent interaction plot (NCIPlot) [29] were used to study the interactions discussed herein by means of the AIMall calculation package [30]. The molecular electrostatic potential surfaces were computed using the Gaussian-16 software and the 0.001 a.u. cutoff for the isosurface. 
Table 1. Crystal data and structure refinement for cocrystals.

\begin{tabular}{|c|c|c|c|c|c|}
\hline Compound & $\left(\right.$ pic)-(D-H $\left.{ }_{2} \mathrm{ma}\right)(1)$ & HOGGOB [31] & JILZOU01 (2a) [32] & JILZOU (2b) [33] & (inam)-(L-H $\left.{ }_{2} \mathrm{ma}\right)(3)$ \\
\hline Empirical formula & $\mathrm{C}_{14} \mathrm{H}_{14} \mathrm{~N}_{2} \mathrm{O}_{4}$ & $\mathrm{C}_{14} \mathrm{H}_{14} \mathrm{~N}_{2} \mathrm{O}_{4}$ & $\mathrm{C}_{14} \mathrm{H}_{14} \mathrm{~N}_{2} \mathrm{O}_{4}$ & $\mathrm{C}_{14} \mathrm{H}_{14} \mathrm{~N}_{2} \mathrm{O}_{4}$ & $\mathrm{C}_{14} \mathrm{H}_{14} \mathrm{~N}_{2} \mathrm{O}_{4}$ \\
\hline Formula weight & 274.27 & 274.27 & 274.27 & 274.27 & 274.27 \\
\hline Temperature/K & $100(2)$ & $100(2)$ & $100(2)$ & $150(2)$ & $100(2)$ \\
\hline Wavelength/A & 0.71073 & 1.54178 & 1.54178 & 0.71073 & 0.71073 \\
\hline Crystal system & Monoclinic & Monoclinic & Monoclinic & Monoclinic & Monoclinic \\
\hline Space group & $P 2_{1} / n$ & $P 2_{1}$ & $P 2_{1}$ & $\mathrm{C} 2$ & $P 2_{1} / c$ \\
\hline$a / \AA$ & $5.4240(3)$ & $5.390(2)$ & $5.2406(3)$ & $32.6557(9)$ & $5.2201(8)$ \\
\hline$b / \AA$ & $26.1177(14)$ & $9.897(3)$ & $10.0477(6)$ & $5.4751(10)$ & $27.662(4)$ \\
\hline$c / \AA$ & $9.3622(5)$ & $24.214(6)$ & $12.6006(7)$ & $14.9264(5)$ & $9.1862(15)$ \\
\hline \multicolumn{6}{|l|}{$\alpha /{ }^{\circ}$} \\
\hline$\beta /{ }^{\circ}$ & $104.715(2)$ & $90.699(13)$ & $95.678(4)$ & $99.400(1)$ & $99.935(10)$ \\
\hline \multicolumn{6}{|l|}{$\gamma /{ }^{\circ}$} \\
\hline Volume $/ \AA^{-3}$ & $1282.77(12)$ & $1291.6(7)$ & $660.24(7)$ & $2632.9(5)$ & $1306.6(4)$ \\
\hline Z & 4 & 4 & 2 & 8 & 4 \\
\hline $\begin{array}{c}\text { Calc. } \\
\text { density } / \mathrm{Mg} / \mathrm{m}^{3}\end{array}$ & 1.420 & 1.410 & 1.380 & 1.384 & 1.394 \\
\hline $\begin{array}{c}\text { Absorp. } \\
\text { coefc. } / \mathrm{mm}^{-1}\end{array}$ & 0.106 & 0.876 & 0.857 & 0.103 & 0.104 \\
\hline$F(000)$ & 576 & 576 & 288 & 1152 & 576 \\
\hline Crystal size & $0.34 \times 0.18 \times 0.12$ & $0.25 \times 0.10 \times 0.03$ & $0.28 \times 0.18 \times 0.16$ & $0.46 \times 0.07 \times 0.07$ & $0.54 \times 0.26 \times 0.16$ \\
\hline$\theta$ range $/^{\circ}$ & 2.381-27.484 & $1.82-66.57$ & $3.52-67.60$ & $3.77-27.43$ & $2.368-29.571$ \\
\hline Limiting indices $/ h, k, l$ & $\begin{array}{c}-7 / 6,-33 / 33 \\
-12 / 12\end{array}$ & $\begin{array}{c}-6 / 6,-11 / 11 \\
-28 / 28\end{array}$ & $\begin{array}{c}-6 / 6,-9 / 11 \\
-15 / 14\end{array}$ & $\begin{array}{c}-42 / 41,-6 / 7 \\
-15 / 19\end{array}$ & $\begin{array}{c}-7 / 7,-38 / 38 \\
-12 / 12\end{array}$ \\
\hline Absorp. correct. & Multiscan & Multiscan & Multiscan & Multiscan & Multiscan \\
\hline Max. / min. transm. & $1.000-0.946$ & $1.000-0.832$ & $1.000-0.909$ & $1.000-0.569$ & $1.000-0.913$ \\
\hline Data/parameters & $2926 / 196$ & $4517 / 365$ & $1235 / 183$ & $5773 / 385$ & $3655 / 196$ \\
\hline Goodness-of-fit on $F^{2}$ & 1.026 & 1.066 & 1.011 & 1.122 & 1.097 \\
\hline Final $R$ indices & $\begin{array}{c}R_{1}=0.0378 \\
w R_{2}=0.0871\end{array}$ & $\begin{array}{c}R_{1}=0.0271 \\
w R_{2}=0.0695\end{array}$ & $\begin{array}{c}R_{1}=0.0430 \\
w R_{2}=0.1138\end{array}$ & $\begin{array}{c}R_{1}=0.0550 \\
w R_{2}=0.1278\end{array}$ & $\begin{array}{r}R_{1}=0.0468 \\
w R_{2}=0.1149\end{array}$ \\
\hline$R$ indices (all data) & $\begin{array}{c}R_{1}=0.0492 \\
w R_{2}=0.0936\end{array}$ & $\begin{array}{c}R_{1}=0.0287 \\
w R_{2}=0.0708\end{array}$ & $\begin{array}{c}R_{1}=0.0472 \\
w R_{2}=0.1174\end{array}$ & $\begin{array}{c}R_{1}=0.0703 \\
w R_{2}=0.1374\end{array}$ & $\begin{array}{c}R_{1}=0.0633 \\
w R_{2}=0.1234\end{array}$ \\
\hline $\begin{array}{l}\text { Largest dif. } \\
\text { peak/hole }\end{array}$ & $0.305 /-0.248$ & $0.159 /-0.189$ & $0.306 /-0.248$ & $0.291 /-0.298$ & $0.444 /-0.276$ \\
\hline CCDC number & 2072590 & 977791 & 904263 & 626647 & 2072591 \\
\hline
\end{tabular}

\section{Results and Discussion}

The cocrystallization processes were carried out considering the $\mathrm{p} K_{\mathrm{a}}$ of the mandelic acid and the pyridinecarboxamide isomers as coformers, having the $\mathrm{p} K_{\mathrm{a}}$ values of 3.85 (DL- $\mathrm{H}_{2} \mathrm{ma}$ ), based on the carboxylic group [34], 2.10 (pic), 3.35 (nam) and 3.61 (inam), based on pyridine nitrogen [35]. These compounds were chosen to evaluate the degree of acid proton transfer to the coformers, according to the $\Delta \mathrm{p} K_{\mathrm{a}}$ rule, which can contribute to the study of the salt/cocrystal continuum and provide information related to the ability to predict and control synthesis of cocrystals that contain mandelic acid [36]. According to this rule, it is generally accepted that a salt is formed when the value of $\Delta \mathrm{p} K_{\mathrm{a}}$ is greater than 3, while a value of $\Delta \mathrm{p} K_{\mathrm{a}}$ less than 0 should lead to the formation of cocrystals [37]. The values of $\Delta \mathrm{p} K_{\mathrm{a}}\left(\mathrm{p} K_{\mathrm{a}}\right.$ (protonated base)- $\mathrm{p} K_{\mathrm{a}}($ acid)) calculated for pic, nam and inam are $-1.75,-0.50$ and -0.24 , respectively, so the formation of cocrystals should be expected.

The binary solid forms were characterized using NMR (Supplementary Information, Figures S1-S11) and IR (Supplementary Information, Figures S13 and S14) spectroscopy, powder X-ray diffraction (Supplementary Information, Figure S12), and thermal DSC tech-

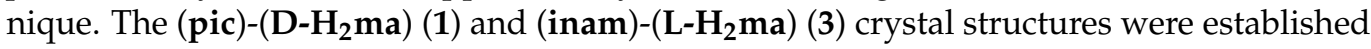
using the single crystal $\mathrm{X}$-ray diffraction technique. The crystal data, experimental details and refinement results are summarized in Table 1. Data of (nam)-(L-H $\left.\mathrm{H}_{2} \mathrm{ma}\right)(\mathbf{2})$ and its crystal structure was taken from the bibliography (JILZOU01 [32]).

\subsection{Crystal Structure Analysis}

Cocrystallization of $\mathbf{D L}-\mathbf{H}_{2}$ ma and pic in 1:1 molar ratio from ethyl acetate produced plate-shaped colorless crystals that belonged to a 1:1 cocrystal, a new polymorph that differs from the one known with a 2:2 pic-D- $\mathbf{H}_{2}$ ma ratio (HOGGOB, [31]). The crystal 
structure was solved in monoclinic space group $P 2_{1} / n$. The crystallographic asymmetric unit consists of one molecule each of $\mathbf{D}-\mathbf{H}_{2} \mathbf{m a}$ and pic (Figure 1a). The crystal structure features an acid-amide heterosynthon $R_{2}^{2}(8)$ between $\mathbf{D}-\mathrm{H}_{2}$ ma and pic involving $\mathrm{O}-\mathrm{H} \cdots \mathrm{O}$ (2.547(1) $\left.\AA, 168.3(2)^{\circ}\right)$ and $\mathrm{N}-\mathrm{H} \cdots \mathrm{O}\left(2.929(2) \AA, 166.6(2)^{\circ}\right)$ hydrogen bonds (Table S1). The anti-N-H of the pic forms an $\mathrm{N}-\mathrm{H} \cdots \mathrm{O}\left(2.948(2) \AA, 126.3(1)^{\circ}\right)$ hydrogen bond with the same carboxylic oxygen atom of a symmetrically related acid molecule, and the hydroxyl $\mathrm{O}-\mathrm{H}$ of the $\mathbf{D}-\mathbf{H}_{2}$ ma forms an O-H $\cdots \mathrm{N}\left(3.071(2) \AA\right.$, 139.9(2) $\left.{ }^{\circ}\right)$ hydrogen bond with the adjacent pyridine $\mathrm{N}$ of the pic, forming a second heterosynthon of graph set $R_{2}^{2}(10)$. Thus, it generates a four-component supramolecular plane unit that consists of each two molecules of $\mathbf{D}-\mathrm{H}_{2} \mathrm{ma}$ and pic, giving rise to a new ring motif $R_{4}^{2}(8)$ in the same way as in the other polymorph [33] (Figure 1b).

Although little is known about the crystallization mechanisms involving the stages of molecular aggregation to form cocrystals [38], in this case it is likely that the mechanism is likely to include a first stage of molecular recognition between an acid molecule and another of amides, the well-known amide-acid heterosynthon. In a second stage, two of these heterodimers, symmetrically related, are associated by establishing new hydrogen bonds, to form the above tetrameters (Figure 1b).

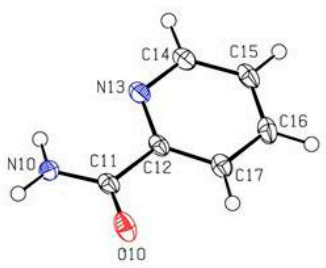

(a)

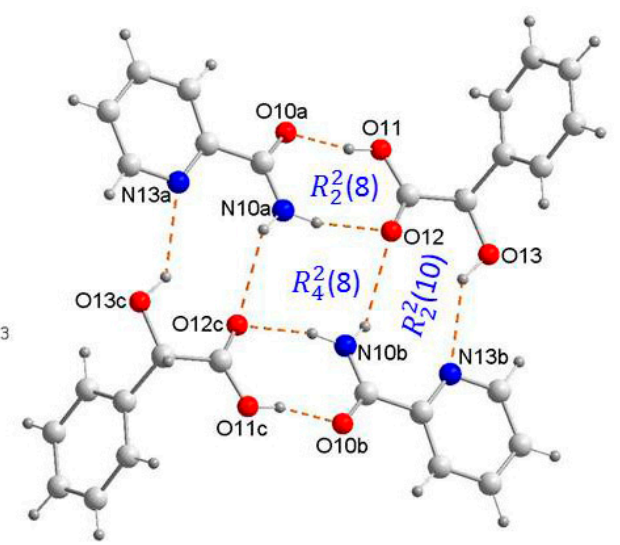

(b)

Figure 1. (a) A view of the molecular structure of 1 showing atomic labeling and displacement ellipsoids drawn at the $50 \%$ probability level, and (b) four-component supramolecular unit showing the intermolecular interactions and the supramolecular synthons. Hydrogen bonds are shown as orange dashed lines. See Table S1 for symmetry codes.

Another aspect to consider is the molecular conformation of each of the cocrystals and the difference between them and with mandelic acid and the conformers. Conformational flexibility of pyridinecarboxamides is related to the torsion angle of the amide group in relation to the pyridine ring $\left(\theta_{1}\right)$, and in mandelic acid to the torsion angles involving the carbonyl group of the carboxylic acid $\left(\theta_{2}\right)$ and the group hydroxyl of the alcohol group $\left(\theta_{3}\right)$ (Scheme 1). Table 2 compares the molecular conformations of pyridinecarboxamides and mandelic acid in these cocrystals. 
Table 2. Torsional angles of pyridinecarboxamides and mandelic acid crystals and corresponding cocrystals.

\begin{tabular}{|c|c|c|c|c|c|}
\hline Compound & Polymorph & $\theta_{1} *$ & $\theta_{2} *$ & $\theta_{3} *$ & Molecule \\
\hline pic & I & -161.3 & & & \\
\hline DL- $\mathrm{H}_{2} \mathrm{ma}$ & I & & -105.0 & -65.8 & \\
\hline \multirow[t]{2}{*}{ DL-H ${ }_{2} \mathrm{ma}$} & II & & -122.1 & -91.5 & 1 \\
\hline & II & & -125.7 & -42.5 & 2 \\
\hline 1 & & -168.5 & -111.0 & -25.8 & \\
\hline \multirow[t]{2}{*}{ HOGGOB [31] } & & -173.3 & 125.5 & 90.9 & 1 \\
\hline & & 175.5 & -79.2 & 54.3 & 2 \\
\hline \multirow[t]{3}{*}{ nam } & $\alpha$ & 157.6 & & & \\
\hline & $\varepsilon$ & 26.8 & & & \\
\hline & $\iota$ & 151.5 & & & \\
\hline \multirow[t]{2}{*}{$\mathrm{D}-\mathrm{H}_{2} \mathrm{ma}$} & & & -124.5 & -80.5 & 1 \\
\hline & & & -122.0 & -30.5 & 2 \\
\hline JILZOU01 (2a) [32] & & -28.7 & -106.1 & -72.8 & \\
\hline \multirow[t]{2}{*}{ JILZOU (2b) [33] } & & 35.3 & -129.6 & -48.2 & 1 \\
\hline & & 12.0 & -103.5 & -41.6 & 2 \\
\hline \multirow[t]{3}{*}{ inam } & I & 30.5 & & & \\
\hline & III & 30.9 & & & \\
\hline & $\mathrm{V}$ & 19.6 & & & \\
\hline \multirow[t]{4}{*}{$\mathrm{L}-\mathrm{H}_{2} \mathrm{ma}$} & I & & 119.4 & 22.9 & 1 \\
\hline & & & 120.1 & -87.4 & 2 \\
\hline & II & & 115.5 & 10.9 & 1 \\
\hline & & & 116.8 & 100.0 & 2 \\
\hline 3 & & -0.5 & 112.4 & 73.5 & \\
\hline
\end{tabular}

* $\theta_{1}, \theta_{2}$ and $\theta_{3}$ are defined in Scheme 1 ; values of torsional angles were calculated from the crystal structures in CSD.

In 1, the oxygen atom of the amide group is opposite the nitrogen atom of the pyridine ring outside the pyridine plane, in a similar way to that of polymorph I of pure pic. In the mandelic acid molecule, small conformational changes are also observed, more pronounced in $\theta_{3}$, which are consistent with those existing in the second symmetrically independent molecule of $\mathbf{D}-\mathbf{H}_{2} \mathbf{m a}$, and close to those of the second molecule of polymorph II of DL$\mathbf{H}_{\mathbf{2}}$ ma (Table 2). When these values are compared with those of the HOGGOB polymorph, noticeable and more pronounced discrepancies are observed in the torsion angles of the second symmetrically independent acid molecule, not only in $\theta_{3}$ but also in $\theta_{2}$, probably due to the different hydrogen bonds in which the donor alcoholic $\mathrm{OH}$ groups participate.

In crystal packing, the flat units are arranged one next to the other in the plane " $b c$ ", without any interaction (Figure 2a), so that in the direction of the diagonal of the angle between the axes " $a$ " and " $c$ " are arranged intercalated in opposite orientations to form a 3D network with an internal zigzag-like orientation (Figure $2 b$ ). The absence of strong interactions between tetramers may justify for some softer properties in the cocrystals, compared to those of picolinamide. 

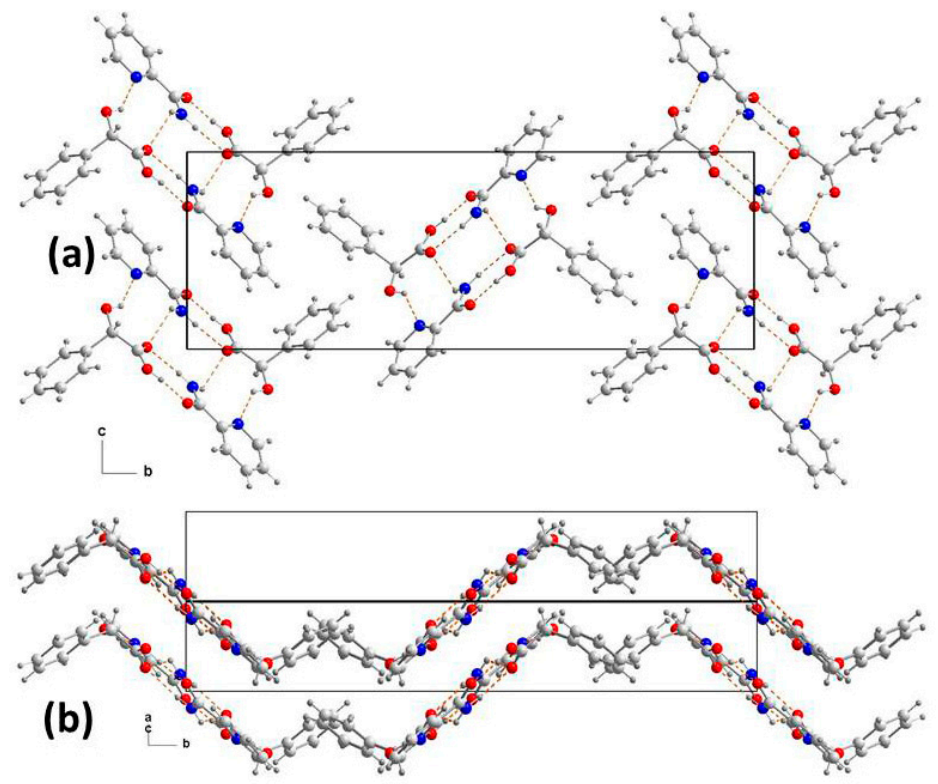

Figure 2. Packing diagram for $\mathbf{1}$, viewed (a) in the "bc" plane and (b) parallel to " $b$ " axis.

From the cocrystallization of DL- $\mathrm{H}_{2} \mathrm{ma}$ and nam are known several structures of different stoichiometries in ratios 1:1, 2:1, 2:2 and 1:4 [23]. In this laboratory, the same (nam)-(D-H $\mathbf{2}$ ma) (1:1) cocrystal was prepared by crystallization from ethyl acetate. Crystal structure analysis of 2 revealed that the cocrystal belongs to monoclinic, $P 2_{1}$ space group with one molecule each of $\mathbf{D}-\mathbf{H}_{\mathbf{2}} \mathbf{m a}$ and nam in the crystallographic asymmetric unit (Figure 3a). The crystal structure features an heterosynthon between the $\alpha$-hydroxyl carbonyl group of $\mathbf{D}-\mathbf{H}_{2}$ ma and the amide group of nam involving $\mathrm{O}-\mathrm{H} \cdots \mathrm{O}(2.708(1) \AA$, $\left.143.3(2)^{\circ}\right)$ and $\mathrm{N}-\mathrm{H} \cdots \mathrm{O}\left(3.002(1) \AA, 155.4(2)^{\circ}\right)$ with ring motif $R_{2}^{2}(9)$ (Table S1). These heterodimers are further joined by hydrogen bonds through $\mathrm{O}-\mathrm{H}$ carboxyl acid and pyridine $\mathrm{N}$ atom $\left(2.684(1) \AA, 175.0(2)^{\circ}\right)$, which is accompanied by a stabilizing $\mathrm{C}-\mathrm{H} \cdots \mathrm{O}$ hydrogen bond $(\mathrm{H} \cdots \mathrm{O}, 2.342 \AA ; \mathrm{C} \cdots \mathrm{O}, 3.103 \AA)$, resulting in a supramolecular synthon of graph set $R_{2}^{2}(7)$. In addition, the amide anti-N-H and hydroxy $\mathrm{O}$ atom $\mathrm{N}-\mathrm{H} \cdots \mathrm{O}(2.921(1) \AA$, $\left.144.9(1)^{\circ}\right)$ form heterosyntons of graph set $R_{4}^{3}(11)$, to originate a new four-component supramolecular unit that is repeated along infinite ribbons (Figure 3b). In the 3D network, these heterodimers are further joined by hydrogen bonds to form independent layers along "b" axis (Figure 4a) [32], extending in the "ca" plane simulating a zigzag chain that, unlike 1 (Figure 2b), all molecules are oriented in the same way (Figure $4 b$ ).

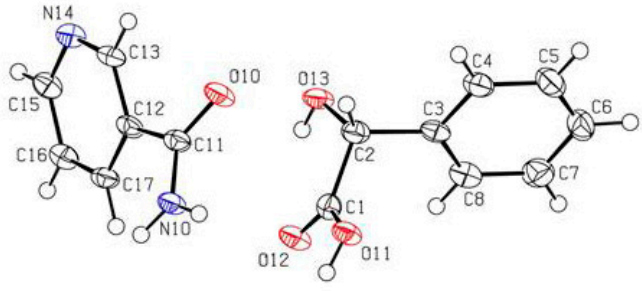

(a)

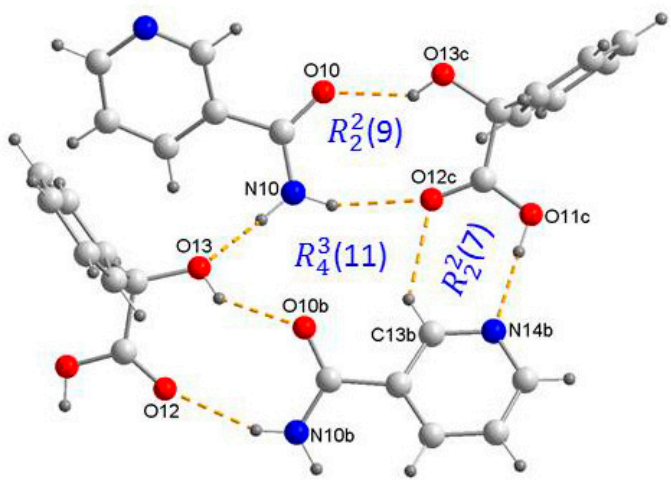

(b)

Figure 3. (a) A view of the molecular structure of 2 showing atomic labeling and displacement ellipsoids drawn at the $50 \%$ probability level, and (b) four-component supramolecular unit showing the hydrogen patterns, as orange dashed lines, observed in 2 . See Table S1 for symmetry codes. 

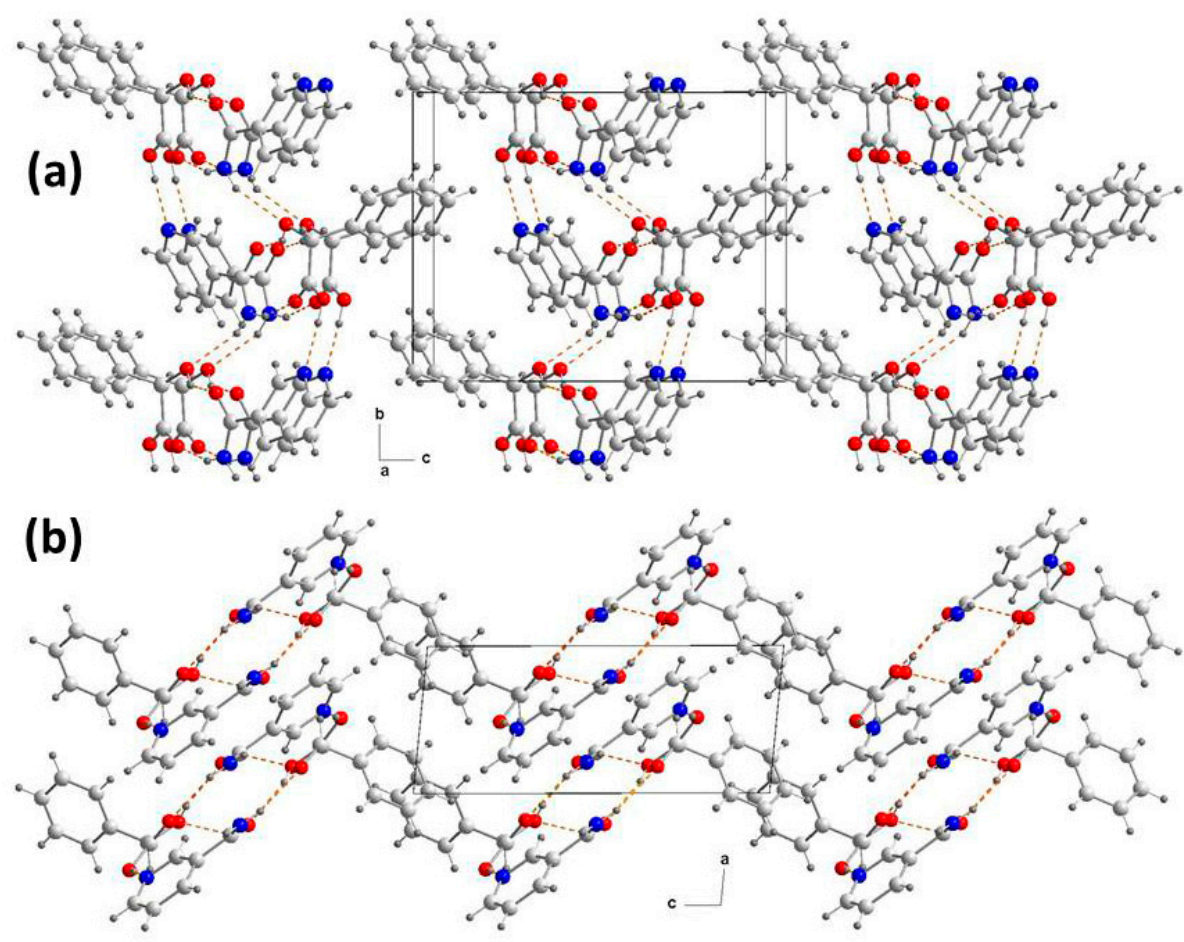

Figure 4. Packing diagram for 2 , viewed (a) in the "bc" plane and (b) in the "ca" plane.

In the 2 system, taking as reference the data of the structure of the polymorph $\varepsilon$ (NICOAM07, from the CSD), in the crystals of pure nam it is observed that the $\mathrm{O}$ atom of the amide group is on the same side of the atom nitrogen of the pyridine ring $\left(\theta_{1}, 26.8^{\circ}\right)$, which is the same conformation adopted by the polymorphs JILZOU01 [32] $\left(-28.7^{\circ}\right)$ and JILZOU [33] (35.3 and $12.0^{\circ}$ ). It should be noted that this conformation is opposite to that described above for the cocrystals of $\mathbf{1}$. Regarding the $\mathbf{D}-\mathbf{H}_{\mathbf{2}}$ ma molecule in the cocrystal, differences in conformation are also observed, as can be seen in the values of $\theta_{2}$ and $\theta_{3}$ compared with those of the two symmetrically independent molecules of the acid, although they do not differ in excess of those found in HOGGOB molecule 1 [31] (Table 2).

The new cocrystals of $\mathbf{D L}-\mathbf{H}_{\mathbf{2}}$ ma with inam in a 1:1 ratio, prepared by crystallization in ethyl acetate, have also been previously obtained in warm ethanol [6]. The crystal structure revealed that cocrystals 3 belong to the monoclinic space group, $P 2_{1} / c$ with one molecule of each coformer in the asymmetric crystal unit (Figure $5 \mathrm{a}$ ). $\mathbf{L}-\mathbf{H}_{\mathbf{2}} \mathbf{m a}$ and inam interact with each other via an acid-pyridine heterosynthon involving $\mathrm{O}-\mathrm{H} \cdots \mathrm{N}$ $\left(2.624 \AA, 177.3^{\circ}\right)$ hydrogen bond (Table S1). As in 2 , the $\mathrm{N}_{\mathrm{py}} \cdots \mathrm{H}-\mathrm{O}$ hydrogen bond is accompanied by a complementary $\mathrm{C}-\mathrm{H} \cdots \mathrm{O}$ hydrogen bond $(\mathrm{H} \cdots \mathrm{O}, 2.640 \AA$; $\mathrm{C} \cdots \mathrm{O}, 3.131 \AA$, $\mathrm{CHO} 127.9^{\circ}$ ). The amide group forms a amide-amide homosynthon dimers of typical ring motif $R_{2}^{2}(8)$ between inam molecules involving $\mathrm{N}-\mathrm{H} \cdots \mathrm{O}\left(2.881(1) \AA, 179.7(2)^{\circ}\right)$. At the same time, these dimers are attached to $\mathbf{L}-\mathbf{H}_{\mathbf{2}} \mathbf{m a}$ molecules in two ways. One is through a O-H $\cdots$ O bond formed between the hydroxyl $\mathrm{O}-\mathrm{H}$ and the amide $\mathrm{O}$ of a nearest neighboring acid molecule $\left(2.775(1) \AA, 162.9(2)^{\circ}\right)$ whereas the second one is via $\mathrm{N}-\mathrm{H} \cdots \mathrm{O}$ (2.949(1) $\left.\AA, 141.7(1)^{\circ}\right)$ between the amine anti-N-H and the hydroxy oxygen of the L$\mathbf{H}_{2}$ ma (Figure $5 b$ ), which is reinforced by a hydrogen bond $\mathrm{C}-\mathrm{H} \cdots \mathrm{O}$ in which carbonyl participates, originating a heterosynthon of graph set $R_{2}^{2}(10)$ (Figure $5 \mathrm{~b}$ ). 


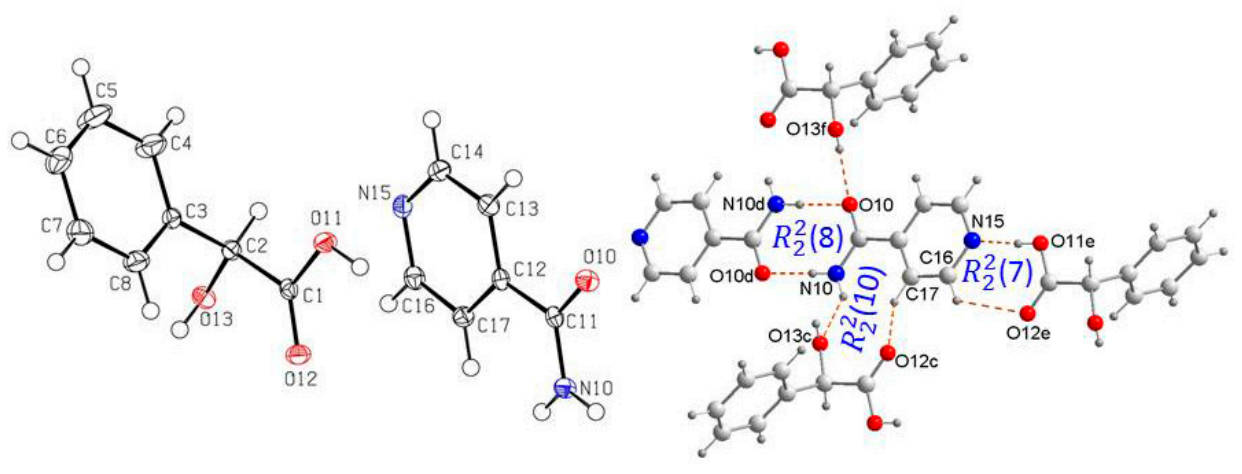

(a)

(b)

Figure 5. (a) A view of the molecular structure of 3 showing atomic labeling and displacement ellipsoids drawn at the 50\% probability level, and (b) primary hydrogen-bond interactions in 3 . Hydrogen bonds are shown as orange dashed lines. See Table S1 for symmetry codes.

In 3 , inam is practically planar $\left(\theta_{1},-0.5^{\circ}\right)$, which contrasts with the values of this torsion angle found in polymorphs I, III and V of the pyridinecarboamide (Table 2). Conformational differences are also observed in the $\mathbf{L}-\mathbf{H}_{2}$ ma molecule. Note especially that the four molecules of the two polymorphs of $\mathbf{L}-\mathrm{H}_{2}$ ma have substantially different conformations from those found in the cocrystal, particularly $\theta_{3}$.

Another way to describe the hydrogen bond interactions in the crystal packing is considering two self-complementary amide-amide pairwise homosynthon dimers between inam mutually parallel molecules linked through two molecules of mandelic acid each by hydrogen bonds of $\mathrm{O}-\mathrm{H} \cdots \mathrm{O}$ type between $\mathrm{OH}$ of the alcohol group and the carbonyl $\mathrm{O}$ atom of each symmetrically related amide, giving rise to a supramolecular dimer of graph set $R_{4}^{4}(12)$, in the direction of the "a" axis (Figure 6a), and also in the plane "bc" by means of a carboxylic acid-pyridine interaction forming supramolecular heterosynthons of graph set $R_{6}^{4}(28)$ (Figure 6b). The set of these interactions gives rise to a crystal network constituted by independent layers parallel to the "a" axis (Figure 6c).

In the formation of cocrystals of 3 , the probable mechanism must include a first stage of molecular recognition between two amide molecules to form the well-known amide-amide homosynthon. In a second stage, two of those homodimers, symmetrically related, are associated by hydrogen bonds, to form the aforementioned tetrameters (Figure 6a,b).

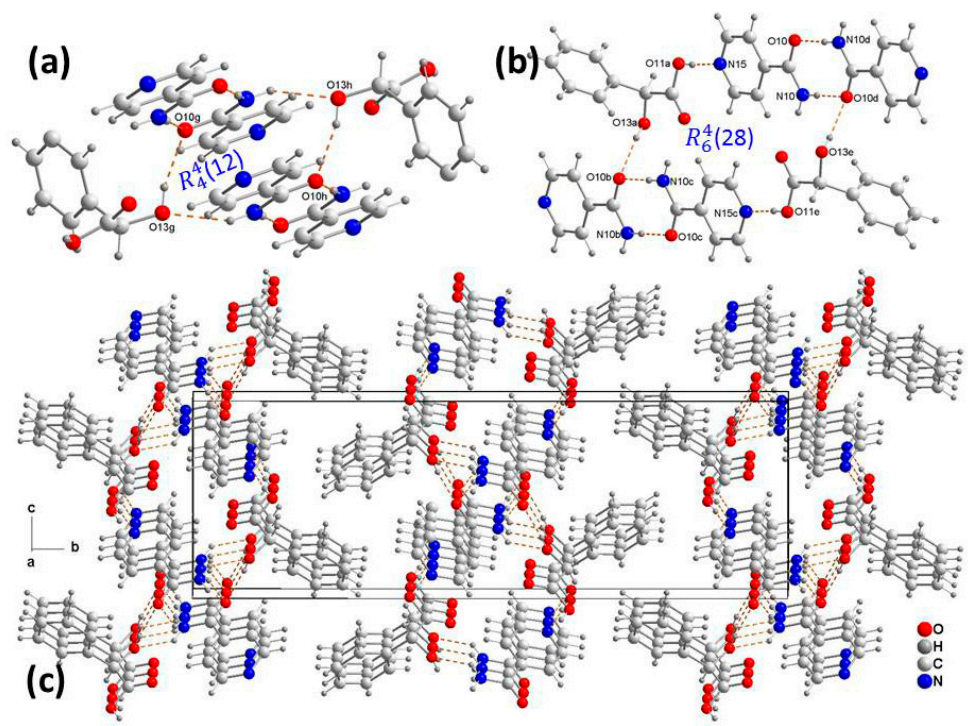

Figure 6. View of amide-amide homosynthon showing (a) $\mathrm{O}-\mathrm{H} \cdots \mathrm{O}$ interactions, (b) $\mathrm{O}-\mathrm{H} \cdots \mathrm{N}_{\text {py }}$ interactions and (c) packing diagram for 3 , viewed in the "bc" plane. 


\subsection{Supramolecular Synthons}

Supramolecular synthons are spatial arrangements of intermolecular interactions between complementary functional groups, and constitute the core of the retrosynthetic strategy for supramolecular structures [39]. With crystal structures defined as networks with the molecules as the nodes and the supramolecular synthons as the connections between them, retrosynthesis can be performed on network structures to produce appropriate molecular structures. The advantage of such an approach in crystal engineering is that comparisons between seemingly different crystal structures are facilitated. If we apply this observation to the systems studied here, we can establish some differences between them that can be attributed to the different constituent isomers.

With the structural data of the cocrystals studied here, we compare the main synthons that they present in their 3D network, which are displayed in Scheme 2. In cocrystal 1, two heteromeric interactions are observed that give rise to two heterosynthons between synamide with carboxylic acid (B) and between pyridine amide with hydroxy carboxylic acid (E). In cocrystal 2, two heteromeric interactions are also observed, causing two heterosynthons, one between pyridine and carboxylic acid (C) and the other between syn-amide and hydroxy carboxylic acid (D). In cocrystal 3, on the contrary, a homomeric interaction corresponding to typical amide-amide homosinton (A) and two heteromeric interactions stand out, one is the heterosinton pyridine with carboxylic acid (C), also observed in the cocrystals of $\mathbf{2}$, and the other anti-amide with hydroxy carboxylic acid (F).

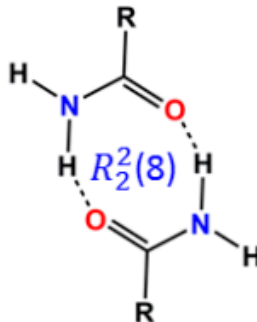

amide-amide

A

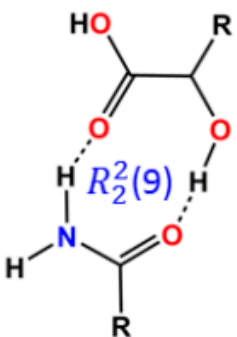

hydroxy carboxylic acidsyn-amide

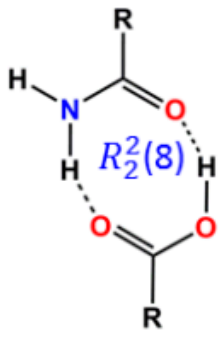

syn-amidecarboxylic acid

B

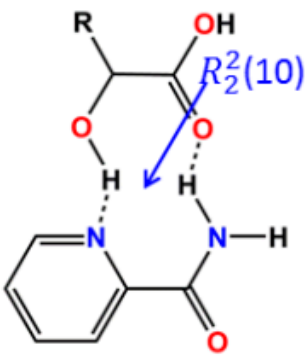

hydroxy carboxylic acidpyridine anti-amide

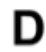

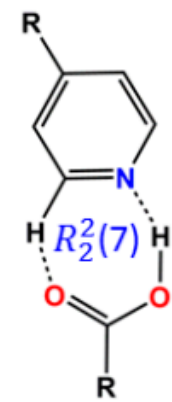

pyridine-

carboxylic acid

C

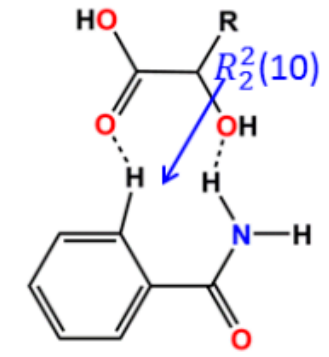

hydroxy carboxylic acidanti-amine

\section{$\mathbf{F}$}

Scheme 2. Main supramolecular synthons in the cocrystals studied herein. Hydrogen bonds are shown as dotted lines.

\subsection{Theoretical DFT Study}

To analyze and understand the different modes of interaction observed in the solid state of the cocrystals, a density functional theory (DFT) study at the PBE0-D3/def2- 
TZVP level of theory was carried out. The recurrent motifs observed in the solid-state $X$-ray structures are analyzed herein, focusing on the calculation of the individual H-bond energies and also the unconventional stacking interactions in compounds $\mathbf{1}$ and $\mathbf{3}$ that include the H-bonded arrays as described below.

Figure 7 shows the molecular electrostatic potential (MEP) surfaces of all coformers (pyridylcarboxamides and mandelic acid) studied in this work. The MEP surface analysis is useful to investigate the electron-rich and electron-poor regions of the crystal coformers. It can be observed that the most positive region corresponds to the $\mathrm{H}$-atom of carboxylic acid $(+58 \mathrm{kcal} / \mathrm{mol})$ in mandelic acid followed by the H-atoms of the carboxamide groups. These are more positive in nicotinamide and isonicotinamide due to the influence of the aromatic $\mathrm{H}$-atom in ortho ( +52 and $+53 \mathrm{kcal} / \mathrm{mol}$ for nicotinamide and isonicotinamide, respectively). Moreover, the most negative regions correspond to the O-atoms of the carboxamide group (ranging from -38 to $-43 \mathrm{kcal} / \mathrm{mol}$ ). The MEP values are also large and negative at the $\mathrm{O}$-atom of the carboxy group in mandelic acid and the aromatic N-atom of nicotinamide and isonicotinamide rings (ranging from -30 to $-35 \mathrm{kcal} / \mathrm{mol}$ ). Finally, the MEP is slightly less negative at the aromatic $\mathrm{N}$-atom of picolinamide $(-17 \mathrm{kcal} / \mathrm{mol})$ and hydroxyl group of mandelic acid $(-27 \mathrm{kcal} / \mathrm{mol})$. This analysis provides evidence that the carboxy group of mandelic acid is the strongest $\mathrm{H}$-bond donor and the $\mathrm{O}$-atom of the carboxamide group the best H-bond acceptor.
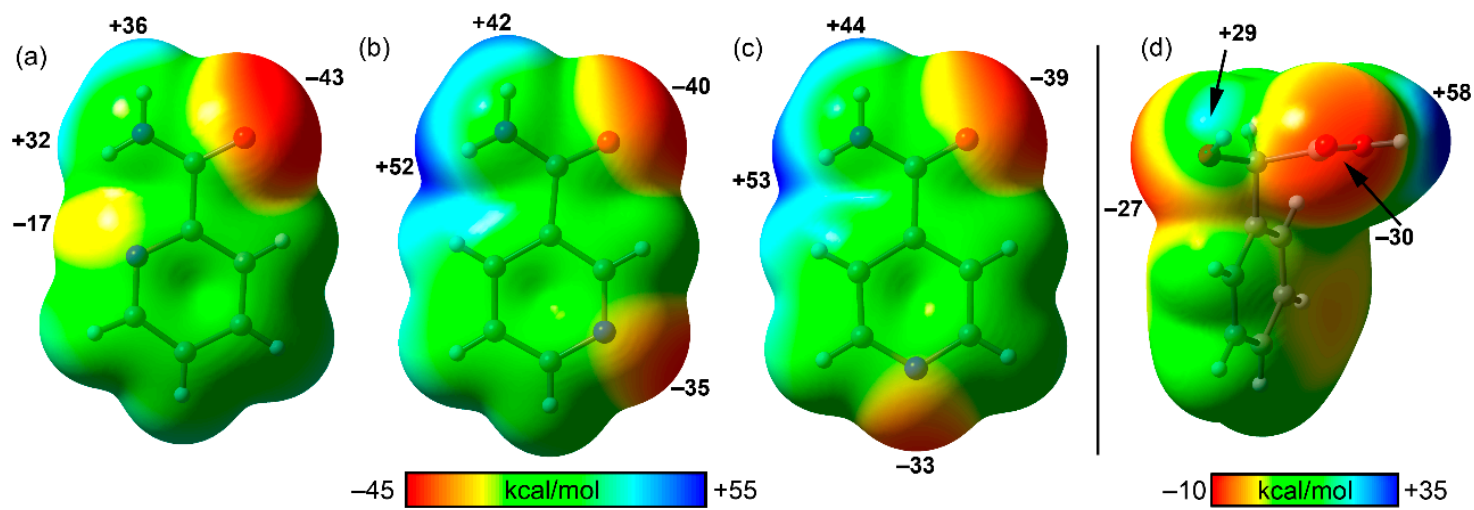

Figure 7. MEP surfaces of picolinamide (a), nicotinamide (b), isoniconitamide (c) and mandelic acid (d) at the PBE0-D3/def2-TZVP level of theory. Isosurfaces plotted using 0.001 a.u. The energies at selected points of the surface are indicated in $\mathrm{kcal} / \mathrm{mol}$.

The hydrogen bond and formation energies of the assemblies were estimated using the QTAIM method and the value of the Lagrangian kinetic G(r) contribution to the local energy density of electrons at the critical point (CP). The dissociation energy of each individual H-bonding interaction was estimated using the approach proposed by Vener et al. [40], which was specifically developed for HBs (Energy $=0.429 \times \mathrm{G}(\mathrm{r})$ at the bond CP).

Figure 8 represents the distribution of bond CPs and bond paths for the tetrameric assembly observed in the picolinamide-mandelic acid cocrystal exhibiting a network of $\mathrm{H}$-bonds. The existence of a bond CP and bond path connecting two atoms is a universal indication of an interaction [41]. The QTAIM analysis of the tetrameric assembly represented in Figure 8a shows the presence of appropriate bond CPs (red spheres) and bond paths connecting the $\mathrm{N} / \mathrm{O}$-atoms to the $\mathrm{H}$ atoms in the $\mathrm{H}$-bonding interactions. Moreover, several ring CPs (yellow spheres) also emerge upon complexation due to the formation of supramolecular rings. The distribution also shows the existence of weak $\mathrm{C}-\mathrm{H} \cdots \mathrm{O}$ interactions between one aromatic $\mathrm{C}-\mathrm{H}$ group and the hydroxyl $\mathrm{O}$-atom of the mandelic acid. The dissociation energy of the tetrameric assembly is large $(39.7 \mathrm{kcal} / \mathrm{mol})$, thus confirming the importance of this H-bonding network. Figure $8 \mathrm{~b}$ also includes the individual energy of each $\mathrm{H}$-bond that is indicated in blue next to the bond $\mathrm{CP}$ that characterizes each H-bond. In agreement with the MEP analysis, the H-bonds involving the carboxy 
group as $\mathrm{H}$-bond donor $(\mathrm{O}-\mathrm{H} \cdots \mathrm{O})$ are the strongest $(11.0$ and $7.8 \mathrm{kcal} / \mathrm{mol})$. Moreover, several structure-guiding motifs are observed in the solid state structure of compound $\mathbf{1}$. These are $R_{2}^{2}(8)$ and $R_{4}^{4}(8)$, involving only the carboxy and carboxamide groups, In addition, a $R_{2}^{2}(10)$ motif is also important, where the pyridine $\mathrm{N}$-atom and the hydroxyl groups participate in addition to the dominant carboxy and carboxamide groups. We also evaluated energetically the formation of a different tetrameric assembly where two $R_{2}^{2}(8)$ motifs are stacked (see Figure 8c) in an antiparallel fashion. The binding energy computed as a dimerization energy of two $R_{2}^{2}(8)$ motifs is $-9.7 \mathrm{kcal} / \mathrm{mol}$, thus revealing the strong nature of this unconventional $\pi$-stacking interaction. The NCIplot index analysis is represented in Figure $8 c$, showing large and green (meaning attractive interaction) isosurfaces located between the carboxy and carboxamide groups of both crystal coformers, thus suggesting that the interaction involves the $\pi$-system of both groups $\left(\pi_{\mathrm{COOH}} \cdots \pi_{\mathrm{CONH}}\right)$. The NCI isosurface is dark blue for the $\mathrm{OH} \cdots \mathrm{O}$ and light blue for the $\mathrm{NH} \cdots \mathrm{O}$ H-bonds of the $R_{2}^{2}(8)$ motifs, thus confirming the strong nature of the $\mathrm{OH} \cdots \mathrm{O}$ bonds in line with the QTAIM dissociation energy and the MEP surface analysis.
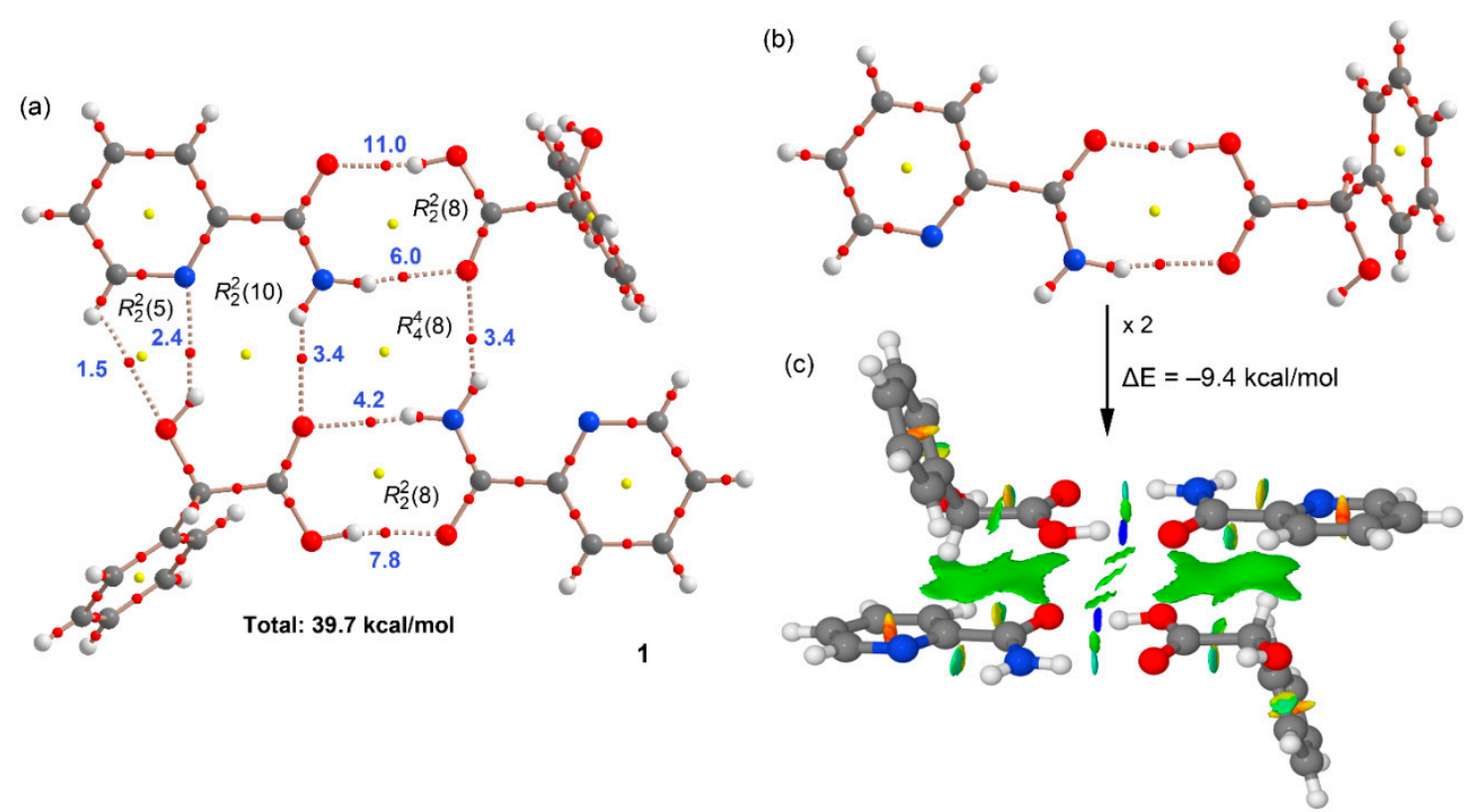

Figure 8. (a) AIM distribution of bond and ring critical points (green and yellow spheres, respectively) and bond paths obtained for the H-bond assembly of compound 1. The dissociation energies of the H-bonds using the G(r) values are indicated next to the bond CPs. (b) AIM distribution of bond and ring critical points (green and yellow spheres, respectively) and bond paths obtained for the H-bonding $R_{2}^{2}(8)$ motif. (c) NCIplot index analysis of the $\pi$-stacked tetramer. $\mid$ RGD I isosurface 0.5 , density cutoff 0.04 a.u., color range: -0.04 a.u. $\leq\left(\operatorname{sign} \lambda_{2}\right) \rho \leq 0.04$ a.u.

For compounds $\mathbf{2 a}$ (JILZOU01) and $\mathbf{2 b}$ (JILZOU), a similar study was performed, where we selected a representative tetrameric assembly for each one including the most important interactions and motifs. The QTAIM analyses are shown in Figure 9, where each $\mathrm{H}$-bond is characterized by a bond $\mathrm{CP}$ connecting the $\mathrm{O} / \mathrm{N}$-atoms to the $\mathrm{H}$-atoms. Similar to 1, the distribution shows the existence of weak $\mathrm{C}-\mathrm{H} \cdots \mathrm{O}$ interactions between $\mathrm{H}$-atoms of nicotinamide ring and the O-atoms of the hydroxyl groups in $\mathbf{2 a}$ or carboxamide group in $\mathbf{2} \mathbf{b}$. Moreover, a recurrent $R_{2}^{2}(7)$ motif is observed in both compounds where the carboxy group of the mandelic acid forms a strong $\mathrm{OH} \cdots \mathrm{N}_{\mathrm{py}} \mathrm{H}$-bond $(8.4$ and $10.4 \mathrm{kcal} / \mathrm{mol}$ in $\mathbf{2 a}$ and $\mathbf{2 b}$, respectively) combined with a much weaker $\mathrm{C}-\mathrm{H} \cdots \mathrm{O}$ H-bond $(2.6$ and $1.7 \mathrm{kcal} / \mathrm{mol}$ in $2 \mathbf{a}$ and $\mathbf{2} \mathbf{b}$, respectively). In $\mathbf{2} \mathbf{a}$, a $R_{2}^{2}(9)$ motif is observed where the hydroxyl group of mandelic acid establishes a moderately strong H-bond $(5.7 \mathrm{kcal} / \mathrm{mol})$ with the carboxamide group of the coformer. An interesting $R_{2}^{2}(8)$ motif is observed in $\mathbf{2 b}$ involving the carboxamide groups ( $4.5 \mathrm{kcal} / \mathrm{mol}$ each H-bond) and leading to the formation of a self-assembled 
dimer. The formation energies of the selected tetramers are similar $(24.6 \mathrm{kcal} / \mathrm{mol}$ in $2 \mathrm{a}$ and $26.9 \mathrm{kcal} / \mathrm{mol}$ in $\mathbf{2 b}$ ).
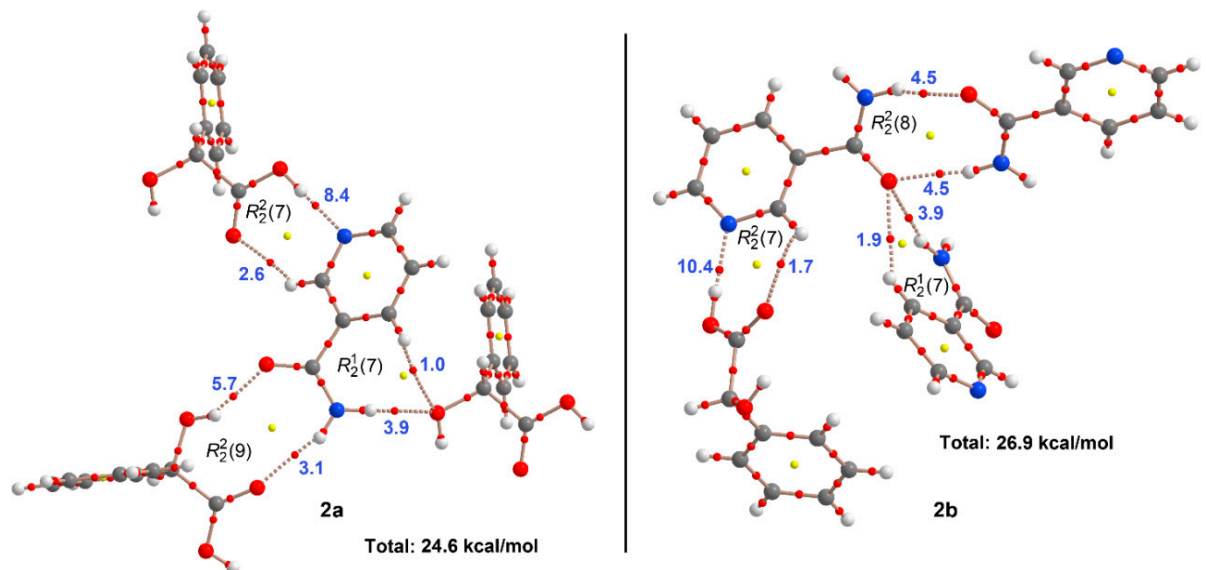

Figure 9. AIM distribution of bond and ring critical points (green and yellow spheres, respectively) and bond paths obtained for the H-bond tetrameric assemblies of compounds $\mathbf{2 a}$ and $\mathbf{2} \mathbf{b}$. The dissociation energies of the H-bonds using the G(r) values are indicated next to the bond CPs.

In compound 3, the tetrameric assembly shown in Figure 10a was analyzed, where the isonicotinamide molecule forms self-assembled dimers via two equivalent $\mathrm{N}-\mathrm{H} \cdots \mathrm{O}$ bonds $\left(R_{2}^{2}(8)\right.$ motif) with a total dissociation energy of $10.4 \mathrm{kcal} / \mathrm{mol}$. In addition, the recurrent $R_{2}^{2}(8)$ motif described above in $\mathbf{2 a}$ and $\mathbf{2 b}$ is also observed in $\mathbf{3}$ with a dissociation energy of $13.8 \mathrm{kcal} / \mathrm{mol}$, thus revealing that the combination of the strong $\mathrm{OH} \cdots \mathrm{H}$ and weak $\mathrm{CH} \cdots \mathrm{O} \mathrm{H}$-bonds is energetically favored over the two symmetric $\mathrm{NH} \cdots \mathrm{O} \mathrm{H}$-bonds between the carboxamide groups. This tetrameric assembly, which presents a very large dissociation energy $(37.0 \mathrm{kcal} / \mathrm{mol})$ self-assembly, forming $\pi$-stacking octamers in the solid state, as represented in Figure 10b. The NCIplot index analysis shows a much extended isosurface that embraces the whole assembly and explaining the large dimerization energy $(-27.3 \mathrm{kcal} / \mathrm{mol})$. The isosurfaces clearly show that the H-bonded arrays are also involved in the stacking interaction, as previously observed in the literature [42]. Actually, it has been demonstrated that the formation of $\mathrm{H}$-bonded arrays is energetically enhanced over aromatic surfaces [43].

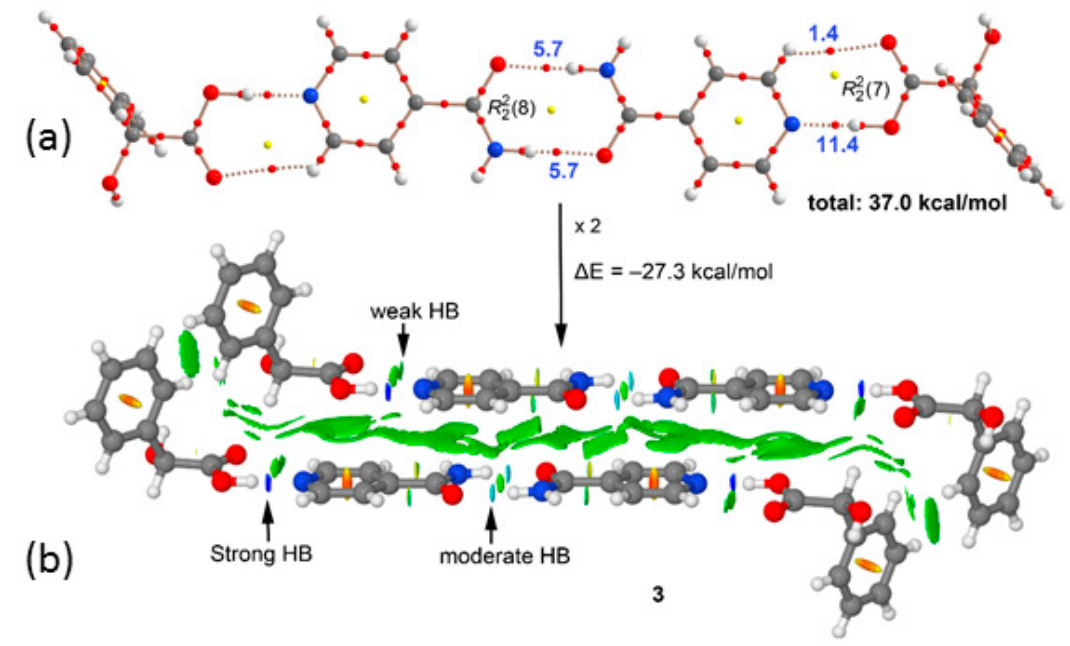

Figure 10. (a) AIM distribution of bond and ring critical points (green and yellow spheres, respectively) and bond paths obtained for the H-bonding assembly of compound 3. The dissociation energies of the H-bonds using the G(r) values are indicated next to the bond CPs. (b) NCIplot index analysis of the $\pi$-stacked octamer. | RGD | isosurface 0.5 , density cutoff 0.04 a.u., color range: -0.04 a.u. $\leq\left(\operatorname{sign} \lambda_{2}\right) \rho \leq 0.04$ a.u. 
Table 3 summarizes the interaction energies for the H-bonding assemblies represented in Figures 8-10 computed using the supramolecular approach (BSSE corrected) and estimated using Verner's equation. In general, there is a good agreement between the BSSE corrected energies and those derived from QTAIM, giving reliability to Verner's approach. In some cases, such as the pentameric assembly of compound $\mathbf{1}$ (Figure 8a) and the tetramer of compound JILZOU (Figure 9b), the interaction energies are greater (in absolute value) than the formation energies derived from the QTAIM approach. This is due to an extra stabilization in those assemblies caused by van der Waals forces and other long-range interactions due to the approximation of the bulk of the molecules. In any case, the H-bonding interactions are clearly dominant.

Table 3. Interaction energies of the $\mathrm{HB}$ assemblies derived from the supramolecular approach (BSSE corrected) and derived from the QTAIM ( $\mathrm{E}_{\mathrm{BSSE}}$ and $\Sigma \mathrm{E}_{\mathrm{HB}}$, respectively) in $\mathrm{kcal} / \mathrm{mol}$ at the PBE0-D3/def2-TZVP level of theory.

\begin{tabular}{|c|c|c|}
\hline Compound & $\mathrm{E}_{\text {BSSE }}$ & $\Sigma \mathrm{E}_{\mathrm{HB}}$ \\
\hline (pic)-(D-H $\mathbf{H}_{\mathbf{2}}$ ma) (1) (Figure 8a) & -42.7 & 39.7 \\
\hline (pic)-(D-H $\mathrm{H}_{2}$ ma) (1) (Figure 8b) & -17.0 & 16.9 \\
\hline JILZOU01 (2a) (Figure 9a) & -22.5 & 24.6 \\
\hline JILZOU (2b) (Figure 9b) & -32.3 & 26.9 \\
\hline (inam)-(L-H $\left.\mathrm{H}_{2} \mathrm{ma}\right)(3)$ (Figure 10a) & -39.5 & 37.0 \\
\hline
\end{tabular}

\subsection{X-ray Powder Diffraction (XRPD) Analysis}

The formation of cocrystals could be verified by XRPD. In Figure 11, each XRPD pattern of mandelic acid cocrystals is different from either that of $\mathbf{D}, \mathbf{L}-\mathbf{H}_{\mathbf{2}} \mathbf{m a}$ or the corresponding coformer. All of the peaks displayed in the measured XRPD patterns of the $\mathbf{D}, \mathbf{L}-\mathbf{H}_{\mathbf{2}} \mathbf{m a}$ cocrystal bulk powder are in close accordance with those in the simulated patterns acquired from single-crystal diffraction data, which confirm the formation of high-purity phases. Similarly, in both cocrystals, the XRPD patterns simulated from the single-crystal structures matches well with the XRPD patterns of powder obtained (Figure S12).
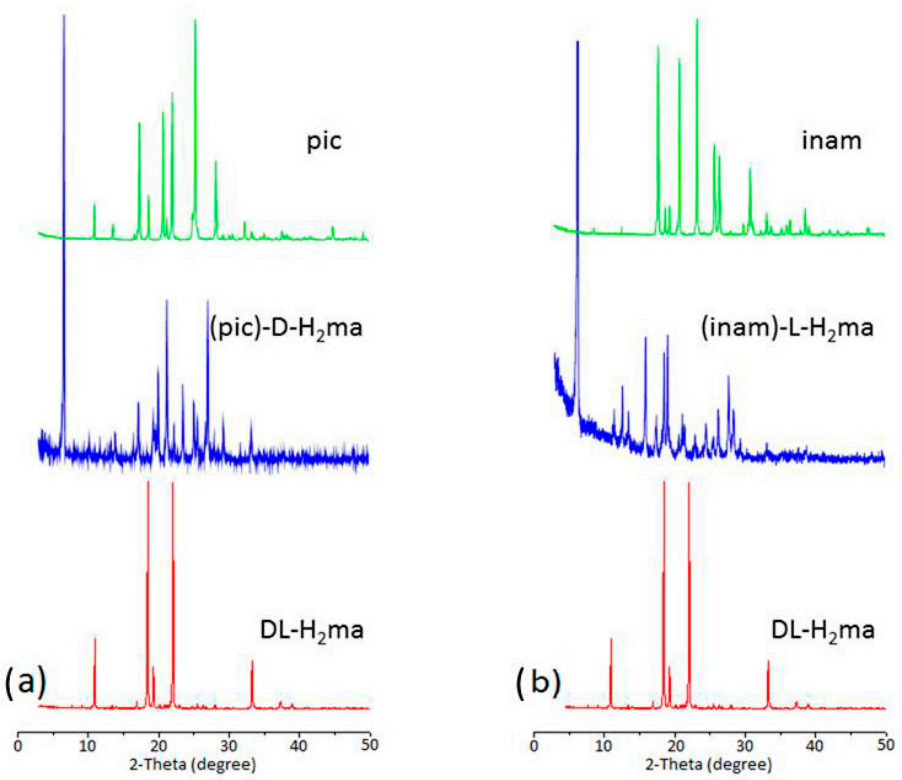

Figure 11. XRPD patterns of mandelic acid (red), pyridinecarboxamides (green) and cocrystal (blue) in (a) 1 and (b) 3. 


\subsection{DSC Analysis}

The thermal behavior of coformers and cocrystals was tested using differential scanning calorimetry (DSC). The DSC heating curves and melting temperatures are represented in Figure 12.

The melting point of the cocrystals, DL-Mandelic acid and pyridinecarboxamides are listed in Table 4 . $\mathbf{H}_{2} \mathbf{m a}$, pic, nam and inam exhibit a sharp melting endotherm followed by decomposition, and do not show any phase change/transformation on heating before

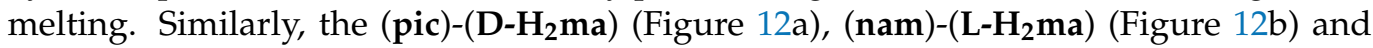
(inam)-(L-H $\left.\mathbf{H}_{2} \mathbf{m a}\right)$ (Figure 12c) binary solids exhibit melting, followed by decomposition. There is no phase change before melting on heating. The cocrystals displayed a lower melting point than the pure mandelic acid and the coformers. The thermal analysis of the cocrystals and their comparison to that of the coformers revealed that in (1) and (3) there is a direct correlation between the melting points of the coformers and the cocrystals (Table 4): the higher the melting point of the coformer, the higher the melting point of the cocrystal. However, in (nam)-( $\left.\mathbf{L}-\mathbf{H}_{\mathbf{2}} \mathbf{m a}\right)$ this trend is broken and its melting point is the lowest of the three cocrystals, probably because the strength of the hydrogen bonds is also the weakest.

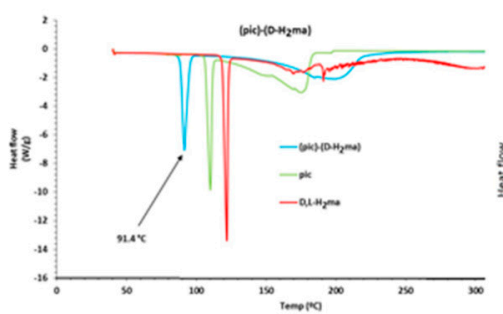

(a)

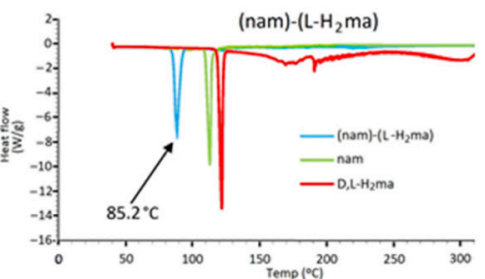

(b)

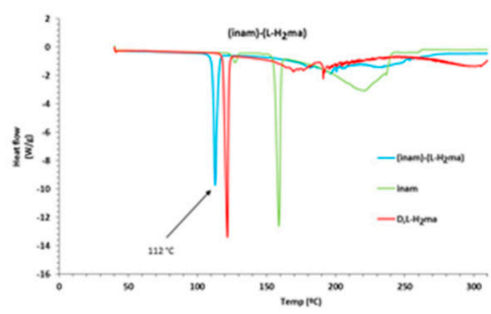

(c)

Figure 12. DSC analyses of the resulting powders of pure components and the cocrystals $1,2 \mathrm{a}$ and 3.

Table 4. Melting points (M. p.) of coformers * and prepared cocrystals.

\begin{tabular}{|c|c|c|c|}
\hline Coformer & M. p. $\left({ }^{\circ} \mathrm{C}\right)$ & Cocrystal & M. p. $\left({ }^{\circ} \mathrm{C}\right)$ \\
\hline DL-Mandelic acid (D,L-H $\mathbf{2} \mathbf{m a})$ & $118-121$ & & \\
\hline D/L-Mandelic acid (L-H $\mathbf{2} \mathbf{m a})$ & $131-135$ & & \\
\hline Picolinamide (pic) & $104-108$ & $\left(\right.$ pic)-(D-H ${ }_{2}$ ma) $(\mathbf{1})$ & 91.4 \\
\hline Nicotinamide (nam) & $128-131$ & $\left(\right.$ nam)-(L-H $\left.{ }_{2} \mathbf{m a}\right)(\mathbf{2})[25]$ & 85.2 \\
\hline Isonicotinamide (inam) & $155-157$ & $($ inam $)-\left(\mathrm{L}-\mathrm{H}_{2} \mathrm{ma}\right)(3)$ & 112.0 \\
\hline
\end{tabular}

* Taken from http://www.chemspider.com/.

\subsection{Thermal Analysis}

To determine the thermal stability of cocrystals, thermogravimetric analysis (TGA) was performed under a stream of air in the range $25-300{ }^{\circ} \mathrm{C}$. Considering that the compounds are thermally stable until a $10 \%$ weight loss of the sample occurs, it can be seen that (1) is stable up to $179{ }^{\circ} \mathrm{C}$, very similar to mandelic acid, while (3) undergoes a $10 \%$ weight loss when $209^{\circ} \mathrm{C}$ is reached, so that its stability is comparable to that of isonicotinamide (Figure 13). Above these temperatures a slow weight loss is observed up to $300^{\circ} \mathrm{C}$, decomposing and releasing $\mathrm{CO}, \mathrm{CO}_{2}$ and various nitrogen oxides, not resulting in final solid waste. The phase purity of the as-synthesized samples could be confirmed by the PXRD pattern, where the characteristic peaks match well with those of the simulated PXRD pattern based on the single crystal data (Figure S10). 

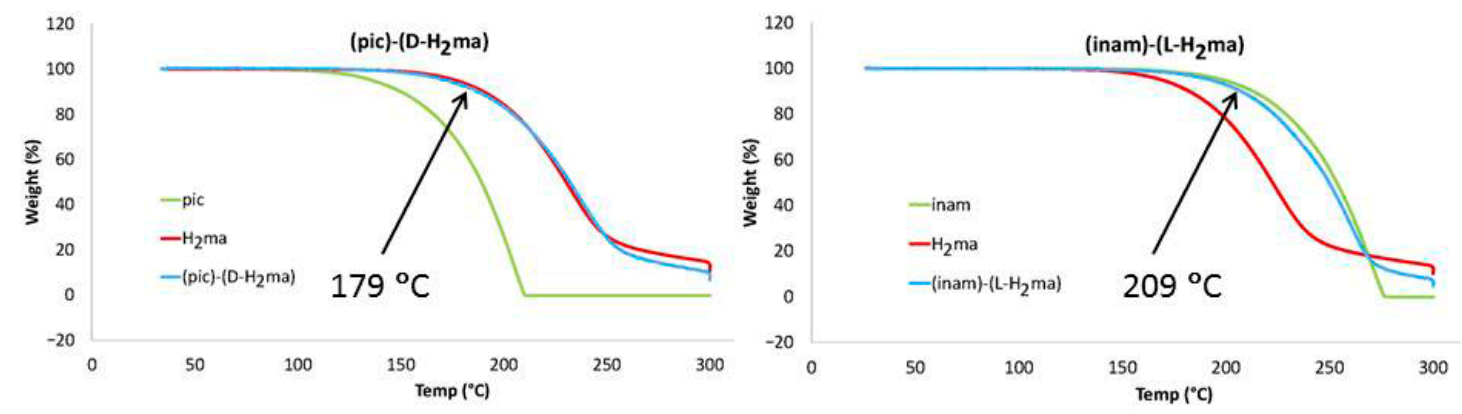

Figure 13. TG thermograms of pure components and the cocrystals $\mathbf{1}$ (left) and $\mathbf{3}$ (right).

\subsection{FT-IR Spectroscopy}

The IR spectra of cocrystals 1 and $\mathbf{3}$ are depicted in Figures S13 and S14, respectively. A comparison with the spectra of its coformers is represented in Figure 14. Regions 3500-3000 and $1700-600 \mathrm{~cm}^{-1}$ are important sources of information about the molecular interactions, because these two regions are associated with hydrogen bonding interaction. In solid DL-mandelic acid, these bands correspond to $3397 \mathrm{~cm}^{-1}, v(\mathrm{OH}), 1716 \mathrm{~cm}^{-1}, v(\mathrm{C}=\mathrm{O})$ and 1078-1064 $\mathrm{cm}^{-1}, v(\mathrm{C}-\mathrm{O})$ [44], while that in pyridine carboxamides appear at 3414 and $3164 \mathrm{~cm}^{-1}, v\left(\mathrm{NH}_{2}\right), 1658 \mathrm{~cm}^{-1}, v(\mathrm{C}=\mathrm{O}), 1603 \mathrm{~cm}^{-1}, \delta\left(\mathrm{NH}_{2}\right), 1386 \mathrm{~cm}^{-1}, v(\mathrm{CN})$ and $640-629 \mathrm{~cm}^{-1}, \alpha(\mathrm{CCC})$, in picolinamide; and 3362 and $3178 \mathrm{~cm}^{-1}, v\left(\mathrm{NH}_{2}\right), 1655 \mathrm{~cm}^{-1}$, $v(\mathrm{C}=\mathrm{O}), 1622 \mathrm{~cm}^{-1}, \delta\left(\mathrm{NH}_{2}\right), 1390 \mathrm{~cm}^{-1}, v(\mathrm{CN})$ and $668-614 \mathrm{~cm}^{-1} 1, \alpha(\mathrm{CCC})$, in isonicotinamide [45]. Consequently, in cocrystals, the absorb peaks around 3400 and $3200 \mathrm{~cm}^{-1}$ attribute to stretching vibrations of $\mathrm{OH}$ and $\mathrm{NH}_{2}$ groups of the acid and of pyridine carboxamides, where the wavenumbers for the asymmetric stretching vibration of $\mathrm{NH}_{2}$ in cocrystal 1 are about $3435 \mathrm{~cm}^{-1}$, while cocrystal 3 shows absorb peaks at about $3379 \mathrm{~cm}^{-1}$ due to stronger hydrogen bond interactions than in 1 . In the $v\left(\mathrm{NH}_{2}\right)$ symmetric stretching vibrations, the same behavior is observed for 3 respective to 1 . For the two cocrystals, the wavenumbers at around $3450 \mathrm{~cm}^{-1}$ indicate the $\mathrm{O}-\mathrm{H} \cdots \mathrm{O}$ hydrogen bond interactions between them, while the slight differences of the wavenumbers for $\mathrm{NH}_{2}$ groups may attribute to the different hydrogen bond interaction experienced by it. While for the region around $1700-600 \mathrm{~cm}^{-1}$, which are corresponding to $\mathrm{C}=\mathrm{O}$ group, the almost identical plots for the two cocrystals, at $1700-1600 \mathrm{~cm}^{-1}$, indicate similar hydrogen bond interactions around the $\mathrm{C}=\mathrm{O}$ groups for pic, and inam in cocrystals $\mathbf{1}$ and 3, respectively, but in $\mathbf{3}$ the band of mean intensity at $1729 \mathrm{~cm}^{-1}$ corresponds to the $\mathrm{C}=\mathrm{O}$ of $\mathbf{H}_{2}$ ma that does not take part in hydrogen bonding, which are in accordance with the structural analysis. We also point out the presence of two new bands at 2506 and $1913 \mathrm{~cm}^{-1}$ for 1 and 2465 and $1891 \mathrm{~cm}^{-1}$ for 3 that result from the $\mathrm{O}-\mathrm{H} \cdots \mathrm{N}_{\text {py }}$ hydrogen bond. This provides clear proof that the hydroxyl or carboxylic group of $\mathbf{H}_{2}$ ma interacts with the aromatic nitrogen of pyridine carboxamides [46]. A similar behavior is deduced when observing the position of in-plane and out-of-plane ring deformation bands of pyridinecarboxyamides in the cocrystals, which reflect a greater strength of the $\mathrm{O}-\mathrm{H} \cdots \mathrm{N}$ interaction in $\mathbf{3}$ than in $\mathbf{1}$ (Table S1), since while in $\mathbf{1}$ it is $\mathrm{O}-\mathrm{H}_{(\text {hydroxyl) }} \cdots \mathrm{N}_{(\text {py })}$ with a distance $\mathrm{O} \cdots \mathrm{N}$ of $3.071 \AA$, in 3 is $2.624 \AA$ for that distance in $\mathrm{O}-\mathrm{H}_{\text {(carboxylic) }} \cdots \mathrm{N}_{(\text {py) }}$. 

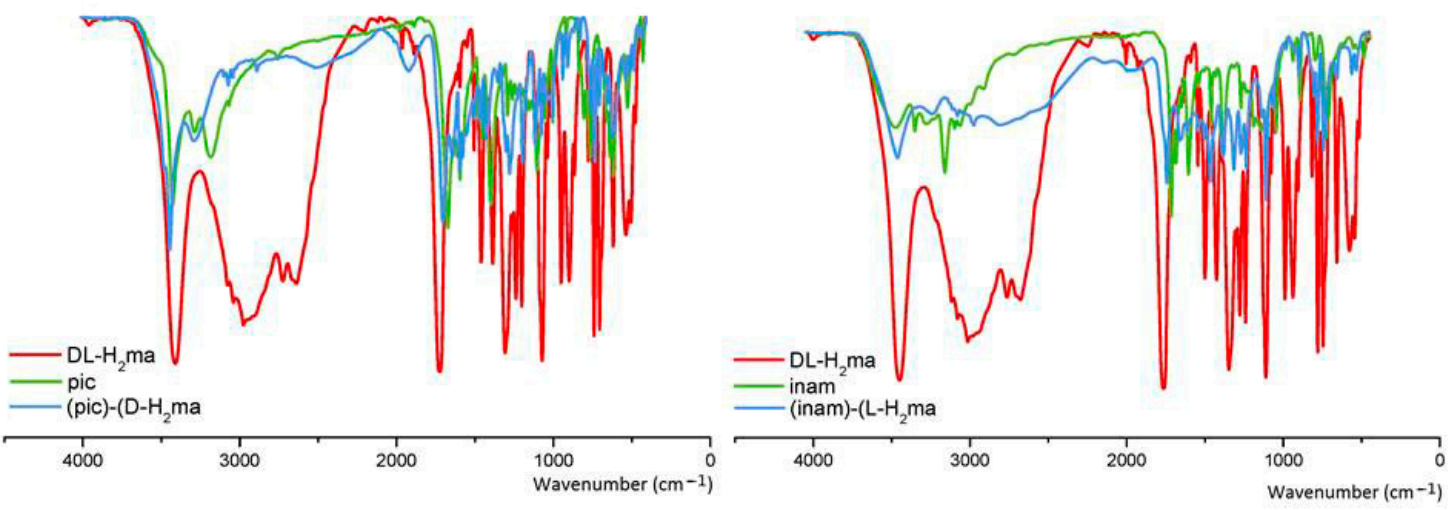

Figure 14. IR spectra of the cocrystals 1 (left) and 3 (right).

\subsection{Solubility and Dissolution}

Drug solubility occurs under a dynamic equilibrium state, which determines the maximum concentration in a saturated solution when excess solid is present in the media. The dissolution rate is a kinetic process that measures the drug concentration, which passes into the media with respect to time. These two parameters are determined by the solvation of the molecular components and the strength of the crystal structure lattice [47]. To improve the drug solubility, the solvent affinity must be increased and/or lower the lattice energy. These can be altered via cocrystal formation, although it is also influenced by the coformer solubility [48]. Since the aqueous solubility values pyridinecarboxyamides are greater than those of $\mathbf{D}, \mathbf{L}-\mathbf{H}_{\mathbf{2}} \mathbf{m a}$, the presence of coformers may appear to improve the dissolution profile of mandelic acid (Figure 15).

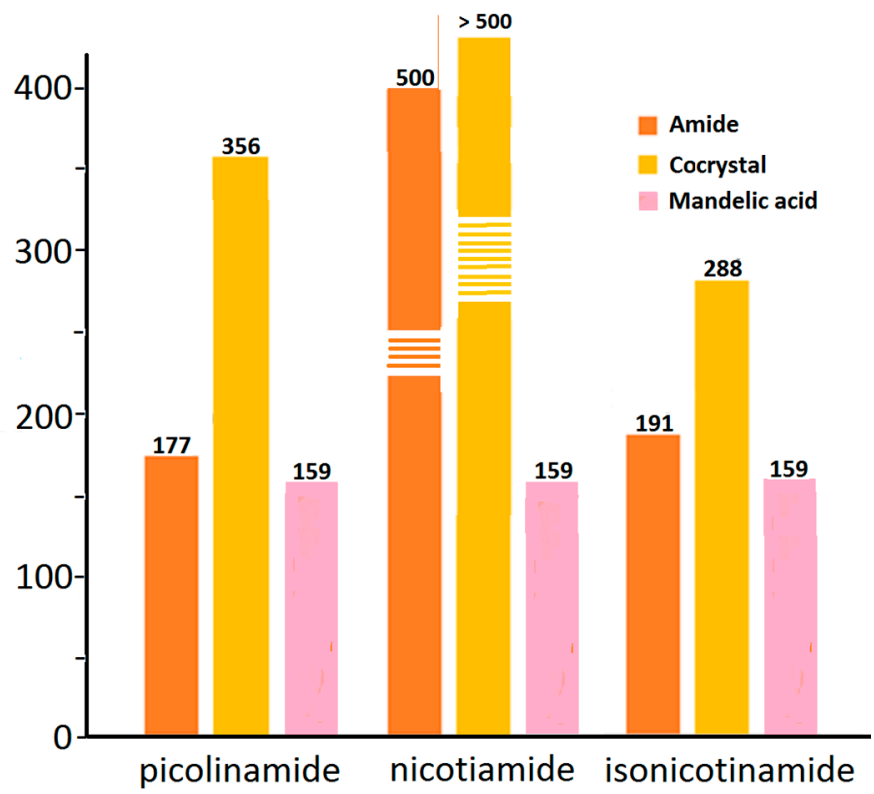

Figure 15. Solubility values in water $\left(\mathrm{mg} \mathrm{mL}^{-1}\right)$ of the coformers and cocrystals $\mathbf{1}-\mathbf{3}$.

\section{Concluding Remarks}

The synthesis and X-ray characterization of two new cocrystals of mandelic acid and pyridylcarboxamides are reported herein. There is competition and interplay of the hydrogen bonding functional groups during binary cocrystallization. The results observed suggest that the hydroxy carboxylic acid forms reliable synthons to afford cocrystals with the pyridinecarboxamides. For the formation of tetramers in $\mathbf{1}$ and 3, a two-stage-based crystallization mechanism is proposed. The first of acid-amide or amide-amide molecular 
recognition, respectively, and the second per association, by hydrogen bond, heterodimers or homodimers, are symmetrically related. The energetic features of the H-bonds were studied using the QTAIM and MEP surface analyses evidencing that the COOH $\cdots \mathrm{N}, \mathrm{O}$ $\mathrm{H}$-bonds are the strongest. Some recurrent motifs, such as $R_{2}^{2}(7)$ between carboxy group and the pyridine ring and the self-assembled $R_{2}^{2}(8)$ motif between the carboxamide groups, are described and analyzed energetically. We believe that the estimation of individual contributions by means of QTAIM analysis reported herein is useful in terms of rationalizing the interactions and for future design and synthesis of cocrystals.

Supplementary Materials: The following supporting information can be downloaded at: https: / / www.mdpi.com/article/10.3390/ cryst12020142/s1, Figure S1: ${ }^{1} \mathrm{H}$ NMR spectra in DMSO-d 6 of cocrystals 1 (upper) and 3 (lower) comparative with their coformers; Figure S2: ${ }^{1} \mathrm{H}$ NMR spectrum

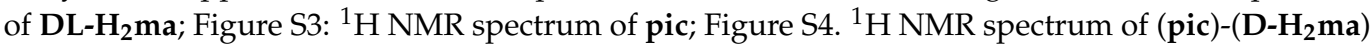
(1); Figure S5: ${ }^{1} \mathrm{H}$ NMR spectrum of inam; Figure S6: ${ }^{1} \mathrm{H}$ NMR spectrum of (inam)-(L-H $\left.\mathbf{H}_{2} \mathbf{m a}\right)$ (3); Figure S7: ${ }^{13} \mathrm{C}$ NMR spectrum of DL- $\mathrm{H}_{2}$ ma; Figure S8: ${ }^{13} \mathrm{C}$ NMR spectrum of pic; Figure S9: ${ }^{13} \mathrm{C}$ NMR spectrum of (pic)-(D-H $\mathbf{H}_{2}$ ma) (1); Figure S10: ${ }^{13} \mathrm{C}$ NMR spectrum of inam; Figure S11: ${ }^{13} \mathrm{C}$ NMR spectrum of (inam)-( $\left.\mathbf{L}-\mathbf{H}_{2} \mathbf{m a}\right)$ (3); Figure S12: XRPD patterns of the solid forms of $\mathbf{1}$ and 3, obtained at room temperature. The XRPD patterns of the cocrystals match well with the simulated XRPD. Table S1: Hydrogen bond parameters $\left[\AA{ }^{\circ}\right]$ for cocrystals. Letters included as superscripts refer to symmetry codes shown in text and figures; Figure S13: IR spectrum of (pic)-(D-H $\mathbf{2} \mathbf{m a})$ (1); Figure S14: IR Spectrum of (inam)-( $\left(\mathrm{L}-\mathrm{H}_{2} \mathrm{ma}\right)(3)$.

Author Contributions: Conceptualization, I.G.-S., R.T.-I. and J.M.G.-P.; methodology, all authors; software, A.F.; validation, A.C., A.F. and J.N.-G.; formal analysis, I.G.-S., R.T.-I. and J.M.G.-P.; investigation, R.T.-I. and J.M.G.-P.; writing-original draft preparation, A.C. and A.F.; writing-review and editing, all authors; visualization, I.G.-S., R.T.-I. and J.M.G.-P.; supervision, A.C., J.N.-G. and A.F.; project administration, A.C., J.N.-G. and A.F.; funding acquisition, A.C. and A.F. All authors have read and agreed to the published version of the manuscript.

Funding: The study received no external funding.

Institutional Review Board Statement: Not applicable.

Informed Consent Statement: Not applicable.

Data Availability Statement: Not applicable.

Acknowledgments: We thank the research groups GI-1580 (USC, Xunta de Galicia) and FQM-283 (Junta de Andalucía) and the "Centre de Tecnologies de la Informació" (Universitat de les Illes Balears, UIB) for free allocation of computer time.

Conflicts of Interest: The authors declare no conflict of interest.

\section{References}

1. Nangia, A.K.; Desiraju, G.R. Crystal Engineering: An Outlook for the Future. Angew. Chem. Int. Ed. 2019, $58,4100-4107$. [CrossRef] [PubMed]

2. Desiraju, G.R.; Vittal, J.J.; Ramanan, A. Crystal Engineering: A Text Book; World Scientific: Singapore, 2011.

3. Desiraju, G.R. Crystal Engineering: From Molecule to Crystal. J. Am. Chem. Soc. 2013, 135, 9952-9967. [CrossRef]

4. Karimi-Jafari, M.; Padrela, L.; Walker, G.M.; Croker, D.M. Creating Cocrystals: A Review of Pharmaceutical Cocrystal Preparation Routes and Applications. Cryst. Growth Des. 2018, 18, 6370-6387. [CrossRef]

5. Solomos, M.A.; Mohammadi, C.; Urbelis, J.H.; Koch, E.S.; Osborne, R.; Usala, C.C.; Swift, J.A. Predicting Cocrystallization Based on Heterodimer Energies: The Case of N,N'-Diphenylureas and Triphenylphosphine Oxide. Cryst. Growth Des. 2015, 15, 5068-5074. [CrossRef]

6. Solomos, M.A.; Watts, T.A.; Swift, J.A. Predicting Cocrystallization Based on Heterodimer Energies: Part II. Cryst. Growth Des. 2017, 17, 5073-5079. [CrossRef]

7. Berry, D.J.; Seaton, C.C.; Clegg, W.; Harrington, R.W.; Coles, S.J.; Horton, P.N.; Hursthouse, M.B.; Storey, R.; Jones, W.; Friščić, T.; et al. Applying Hot-Stage Microscopy to Co-Crystal Screening: A Study of Nicotinamide with Seven Active Pharmaceutical Ingredients. Cryst. Growth Des. 2008, 8, 1697-1712. [CrossRef]

8. Aakeröy, C.B.; Beatty, A.M.; Helfrich, B.A. A High-Yielding Supramolecular Reaction. J. Am. Chem. Soc. 2002, 124, 14425-14432. [CrossRef] [PubMed] 
9. Sarma, B.; Reddy, L.S.; Nangia, A. The Role of $\pi$-Stacking in the Composition of Phloroglucinol and Phenazine Cocrystals. Cryst. Growth Des. 2008, 8, 4546-4552. [CrossRef]

10. Shattock, T.R.; Arora, K.K.; Vishweshwar, P.; Zaworotko, M.J. Hierarchy of Supramolecular Synthons: Persistent Carboxylic Acid ... Pyridine Hydrogen Bonds in Cocrystals That also Contain a Hydroxyl Moiety. Cryst. Growth Des. 2008, 8, $4533-4545$. [CrossRef]

11. Borba, A.; Gómez-Zavaglia, A.; Fausto, R. Molecular Structure, Vibrational Spectra, Quantum Chemical Calculations and Photochemistry of Picolinamide and Isonicotinamide Isolated in Cryogenic Inert Matrixes and in the Neat Low-Temperature Solid Phases. J. Phys. Chem. A 2008, 112, 45-57. [CrossRef]

12. Olsen, R.A.; Liu, L.; Ghaderi, N.; Johns, A.; Hatcher, M.E.; Mueller, L.J. The Amide Rotational Barriers in Picolinamide and Nicotinamide: NMR and ab Initio Studies. J. Am. Chem. Soc. 2003, 125, 10125-10132. [CrossRef] [PubMed]

13. Alvarez-Lorenzo, C.; Castiñeiras, A.; Frontera, A.; García-Santos, I.; González-Pérez, J.M.; Niclós-Gutiérrez, J.; RodríguezGonzález, I.; Vílchez-Rodríguez, E.; Zaręba, J.K. Recurrent motifs in pharmaceutical cocrystals involving glycolic acid: X-ray characterization, Hirshfeld surface analysis and DFT calculations. Cryst. Eng. Comm. 2020, 22, 6674-6689. [CrossRef]

14. Évora, A.O.L.; Castro, R.A.E.; Maria, T.M.R.; Rosado, M.T.S.; Ramos Silva, M.; Canotilho, J.; Eusébio, M.E.S. Resolved structures of two picolinamide polymorphs. Investigation of the dimorphic system behaviour under conditions relevant to co-crystal synthesis. Cryst. Eng. Comm. 2012, 14, 8649-8657. [CrossRef]

15. Li, X.; Ou, X.; Wang, B.; Rong, H.; Wang, B.; Chang, C.; Shi, B.; Yu, L.; Lu, M. Rich polymorphism in nicotinamide revealed by melt crystallization and crystal structure prediction. Commun. Chem. 2020, 3, 152-160. [CrossRef]

16. Aakeröy, C.B.; Beatty, A.M.; Helfrich, B.A.; Nieuwenhuyzen, M. Do Polymorphic Compounds Make Good Cocrystallizing Agents? A Structural Case Study that Demonstrates the Importance of Synthon Flexibility. Cryst. Growth Des. 2003, 3, 159-165. [CrossRef]

17. Li, J.; Bourne, S.A.; Caira, M.R. New polymorphs of isonicotinamide and nicotinamide. Chem. Commun. 2011, 47, 1530-1532. [CrossRef]

18. Eccles, K.S.; Deasy, R.E.; Fábián, L.; Braun, D.E.; Maguired, A.R.; Lawrence, S.E. Expanding the crystal landscape of isonicotinamide: Concomitant polymorphism and co-crystallisation. Cryst. Eng. Comm. 2011, 13, 6923-6925. [CrossRef]

19. Vicatos, A.I.; Caira, M.R. A new polymorph of the common coformer isonicotinamide. Cryst. Eng. Comm. 2019, 21, 843-849. [CrossRef]

20. Van Putten, P.L. Mandelic acid and urinary tract infections. Ant. Van Leeuwenhoek 1979, 45, 622-623. [CrossRef]

21. Cai, W.; Marciniak, J.; Andrzejewski, M.; Katrusiak, A. Pressure Effect on D,L-Mandelic Acid Racemate Crystallization. J. Phys. Chem. C 2013, 117, 7279-7285. [CrossRef]

22. Marciniak, J.; Andrzejewski, M.; Cai, W.; Katrusiak, A. Wallach's Rule Enforced by Pressure in Mandelic Acid. J. Phys. Chem. C 2014, 118, 4309-4313. [CrossRef]

23. Zhang, S.-W.; Harasimowicz, M.T.; de Villiers, M.M.; Yu, L. Cocrystals of Nicotinamide and (R)-Mandelic Acid in Many Ratios with Anomalous Formation Properties. J. Am. Chem. Soc. 2013, 135, 18981-18989. [CrossRef]

24. Young, D.; Ding, F.; Lipparini, F.; Egidi, F.; Goings, J.; Peng, B.; Petrone, A.; Henderson, T.; Ranasinghe, D.; Zakrzewski, V.G.; et al. Gaussian 16, Revision A.01; Gaussian, Inc.: Wallingford, UK, 2016.

25. Weigend, F.; Ahlrichs, R. Balanced basis sets of split valence, triple zeta valence and quadruple zeta valence quality for $H$ to Rn: Design and assessment of accuracy. Phys. Chem. Chem. Phys. 2005, 7, 3297-3305. [CrossRef] [PubMed]

26. Weigend, F. Accurate Coulomb-fitting basis sets for H to Rn. Phys. Chem. Chem. Phys. 2006, 8, 1057-1065. [CrossRef]

27. Adamo, C.; Barone, V. Toward reliable density functional methods without adjustable parameters: The PBE0 model. J. Chem. Phys. 1999, 110, 6158-6169. [CrossRef]

28. Boys, S.F.; Bernardi, F. The calculation of small molecular interactions by the differences of separate total energies. Some procedures with reduced errors. Mol. Phys. 1970, 19, 553-566. [CrossRef]

29. Contreras-García, J.; Johnson, E.R.; Keinan, S.; Chaudret, R.; Piquemal, J.-P.; Beratan, D.N.; Yang, W. NCIPLOT: A Program for Plotting Noncovalent Interaction Regions. J. Chem. Theory Comput. 2011, 7, 625-632. [CrossRef] [PubMed]

30. Keith, T.A. AIMAll (Version 13.05.06); TK Gristmill Software: Overland Park, KS, USA, 2013.

31. Chan, H.C.S.; Woollam, G.R.; Wagner, T.; Schmidtc, M.U.; Lewis, R.A. Can picolinamide be a promising cocrystal former? Cryst. Eng. Comm. 2014, 16, 4365-4368. [CrossRef]

32. Zhang, S.-W.; Guzei, I.A.; de Villiers, M.M.; Yu, L.; Krzyzaniak, J.F. Formation Enthalpies and Polymorphs of Nicotinamide-RMandelic Acid Co-Crystals. Cryst. Growth Des. 2012, 12, 4090-4097. [CrossRef]

33. Friščić, T.; Jones, W. Cocrystal architecture and properties: Design and building of chiral and racemic structures by solid-solid reactions. Faraday Discuss 2007, 136, 167-178. [CrossRef] [PubMed]

34. Gamidi, R.K.; Rasmuson, Å.C. Estimation of Melting Temperature of Molecular Cocrystals Using Artificial Neural Network Model. Cryst. Growth Des. 2017, 17, 175-182. [CrossRef]

35. Kerr, H.E.; Softley, L.K.; Suresh, K.; Hodgkinsona, P.; Evans, I.R. Structure and physicochemical characterization of a naproxenpicolinamide cocrystal. Acta Crystallogr. Sect. C Cryst. Struct. Commun. 2017, 73, 168-175. [CrossRef] [PubMed]

36. Bhogala, B.R.; Basavoju, S.; Nangia, A. Tape and layer structures in cocrystals of some di- and tricarboxylic acids with 4,49bipyridines and isonicotinamide. From binary to ternary cocrystals. Cryst. Eng. Comm. 2005, 7, 551-562. [CrossRef]

37. Cruz-Cabeza, A.J. Acid-base crystalline complexes and the $\mathrm{pK}_{\mathrm{a}}$ rule. Cryst. Eng. Comm. 2012, 14, 6362-6365. [CrossRef] 
38. Lopes, L.C.; Orlando, T.; Simões, P.H.B.; Farias, F.F.S.; Bonacorso, H.G.; Zanatta, N.; Salbego, P.R.S.; Martins, M.A.P. Persistence of $\mathrm{N}-\mathrm{H} \cdots \mathrm{O}=\mathrm{C}$ Interactions in the Crystallization Mechanisms of Trisubstituted Bis-Ureas with Bulky Substituents. Cryst. Growth Des. 2021, 21, 5740-5751. [CrossRef]

39. Desiraju, G.R.; Steiner, T. The Weak Hydrogen Bond in Structural Chemistry and Biology; Oxford University Press: Oxford, UK, 2001.

40. Vener, M.V.; Egorova, A.N.; Churakov, A.V.; Tsirelson, V.G. Intermolecular hydrogen bond energies in crystals evaluated using electron density properties: DFT computations with periodic boundary conditions. J. Comput. Chem. 2012, 33, 2303-2309. [CrossRef]

41. Bader, R.F.W. A Bond Path: A Universal Indicator of Bonded Interactions. J. Phys. Chem. A 1998, 102, 7314-7323. [CrossRef]

42. Guo, D. Sijbesma, R.P.; Zuilhof, H. $\pi$-Stacked Quadruply Hydrogen-Bonded Dimers: $\pi$-Stacking Influences H-Bonding. Org. Lett. 2004, 6, 3667-3670. [CrossRef]

43. Bhattacharyya, M.K.; Saha, U.; Dutta, D.; Frontera, A.; Verma, A.K.; Sharma, P.; Das, A. Unconventional DNA-relevant $\pi$-stacked hydrogen bonded arrays involving supramolecular guest benzoate dimers and cooperative anion $-\pi / \pi-\pi / \pi-$ anion contacts in coordination compounds of Co(ii) and Zn(ii) phenanthroline: Experimental and theoretical studies. New J. Chem. 2020, 44, 4504-4518. [CrossRef]

44. Badawi, H.M.; Förner, W. Analysis of the infrared and Raman spectra of phenylacetic acid and mandelic (2-hydroxy-2phenylacetic) acid. Spectrochim. Acta Part A 2011, 78, 1162-1167. [CrossRef]

45. Bakiler, M.; Bolukbasi, O.; Yilmaz, A. An experimental and theoretical study of vibrational spectra of picolinamide, nicotinamide, and isonicotinamide. J. Mol. Struct. 2007, 826, 6-16. [CrossRef]

46. Castro, R.A.E.; Ribeiro, J.D.B.; Maria, T.M.R.; Ramos Silva, M.; Yuste-Vivas, C.; Canotilho, J.; Eusébio, M.E.S. Naproxen Cocrystals with Pyridinecarboxamide Isomers. Cryst. Growth Des. 2011, 11, 5396-5404. [CrossRef]

47. Suresh, K.; Minkov, V.S.; Namila, K.K.; Derevyannikova, E.; Losev, E.; Nangia, A.; Boldyreva, E.V. Novel Synthons in Sulfamethizole Cocrystals: Structure-Property Relations and Solubility. Cryst. Growth Des. 2015, 15, 3498-3510. [CrossRef]

48. Mannava, M.K.C.; Gunnam, A.; Lodagekar, A.; Shastri, N.R.; Nangia, A.K.; Solomon, K.A. Enhanced solubility, permeability, and tabletability of nicorandil by salt and cocrystal formation. CrystEngComm 2021, 23, 227-237. [CrossRef] 